\title{
MXetronics: MXene-Enabled Electronic and Photonic Devices
}

\author{
Hyunho Kim ${ }^{\circledR}$ and Husam N. Alshareef*() \\ Materials Science and Engineering, Physical Science \& Engineering Division, King Abdullah University of Science and Technology \\ (KAUST), Thuwal, 23955-6900, Saudi Arabia
}

\begin{abstract}
MXenes are a rapidly growing family of twodimensional (2D) materials based on transition-metal carbides and nitrides that have shown great potential as multifunctional nanomaterials. Their unique combination of metallic conductivity, hydrophilicity, and highly charged surfaces endow them with excellent electrochemical performance. Yes, these same characteristics are equally important in electronic and optoelectronic applications of MXenes, which are henceforth termed MXetronics. MXenes are suitable for solution processing in various polar solvents, allowing the preparation of MXene thin films with controlled transparency, sheet resistance, interlayer spacing, and surface chemistry. The wide


selection of various MXene structures, transition-metal compositions, and surface functional groups enables tunable work function, band gap, and hence electronic and optical properties. In this Review, we summarize the recent advances in MXetronics and discuss future possibilities for this rising class of 2D materials.
\end{abstract}

$\mathrm{T}$ ransition-metal carbides and nitrides, known as MXenes, are two-dimensional (2D) derivatives of ternary layered $\mathrm{M}_{n+1} \mathrm{AX}_{n}$ (MAX) phases, where $\mathrm{M}$ is an early transition metal, $\mathrm{A}$ is group IIIA-VIA element, $\mathrm{X}$ is carbon and/or nitrogen, and $n=1-3 .^{1}$ The chemical reaction between MAX phases with F-containing acidic solutions results in selective extraction of $\mathrm{M}-\mathrm{A}$ bonds while $\mathrm{M}-\mathrm{X}$ bonds remain, followed by intercalation-mediated exfoliation. ${ }^{2}$ The broken $\mathrm{M}-\mathrm{A}$ bonds are subject to the spontaneous formation of surface functional groups (denoted as $\mathrm{T}_{x}$, mainly consist of $=\mathrm{O},-\mathrm{OH},-\mathrm{F}$ groups), hence the commonly used MXenes have the general chemical formula $\mathrm{M}_{n+1} \mathrm{X}_{n} \mathrm{~T}_{x}$. The MXene family has recently been expanded to include doubletransition-metal MXene either atomically ordered structures or solid solution, and vacancy-ordered structures by using different combinations of the $\mathrm{M}$ elements. ${ }^{3}$

$\mathrm{Ti}_{3} \mathrm{C}_{2} \mathrm{~T}_{x}$ has been the most studied MXene since its first discovery in 2011. ${ }^{4}$ Coexistence of metallic conductivity and hydrophilic surface featured MXenes in a wide range of applications, including high-performance electrochemical supercapacitors, ${ }^{5,6}$ catalysis, ${ }^{7,8}$ water splitting/purification, ${ }^{9-11}$ electromagnetic interference (EMI) shielding, ${ }^{12}$ transparent/ flexible electrodes, ${ }^{13}$ and gas/mechanical sensors, ${ }^{14,15}$ through a cost-effective solution process. The solution-mediated deposition techniques (such as spin/spray/dip coating, layerby-layer, drop-casting, stamping, transfer, printing, etc.) are low-energy processes that can avoid unwanted damage in the underlying layers and unwanted interfacial defects/states formed by conventional high-energy processes (evaporation, sputtering, etc.). ${ }^{16}$ This is a potentially important aspect in MXetronics, ${ }^{17}$ specifically for van der Waals metal-semiconductor junctions with tunable or vanished Schottky barriers. ${ }^{18}$ In addition, solution deposition processes can be scaled more economically than vacuum deposition methods.

The surface functionality is one of the most interesting features of MXenes. The functional groups are strongly coupled to their properties and allow MXenes to be integrated with various organic materials/ligands. The work functions of MXenes have been reported to cover a wide range, from $1.6 \mathrm{eV}$ for $\mathrm{Sc}_{2} \mathrm{C}(\mathrm{OH})_{2}$ to $8.0 \mathrm{eV}$ for $\mathrm{Cr}_{2} \mathrm{CO}_{2}{ }^{19,20}$ Oxygen and fluorine functionalization give higher work functions, because of their high electronegativity, while hydroxyl groups give an ultralow work function, because of the strong surface dipole moment. ${ }^{19,21}$ Most MXenes are known to have metallic band structures, while a few systems are expected to be semiconductors. Some MXenes have been predicted to have magnetic properties. The diverse electronic and magnetic properties of $\mathrm{M}_{2} \mathrm{XT}_{x}$ MXenes are summarized in Figure 1, based on theoretical predictions. The reported band-gap values are also given in Table 1 for semiconducting MXenes. It is clearly seen that these characteristics are strongly dependent on the choice of transition metal atoms, surface functional

Received: September 30, 2019

Accepted: November 13, 2019

Published: November 13, 2019 

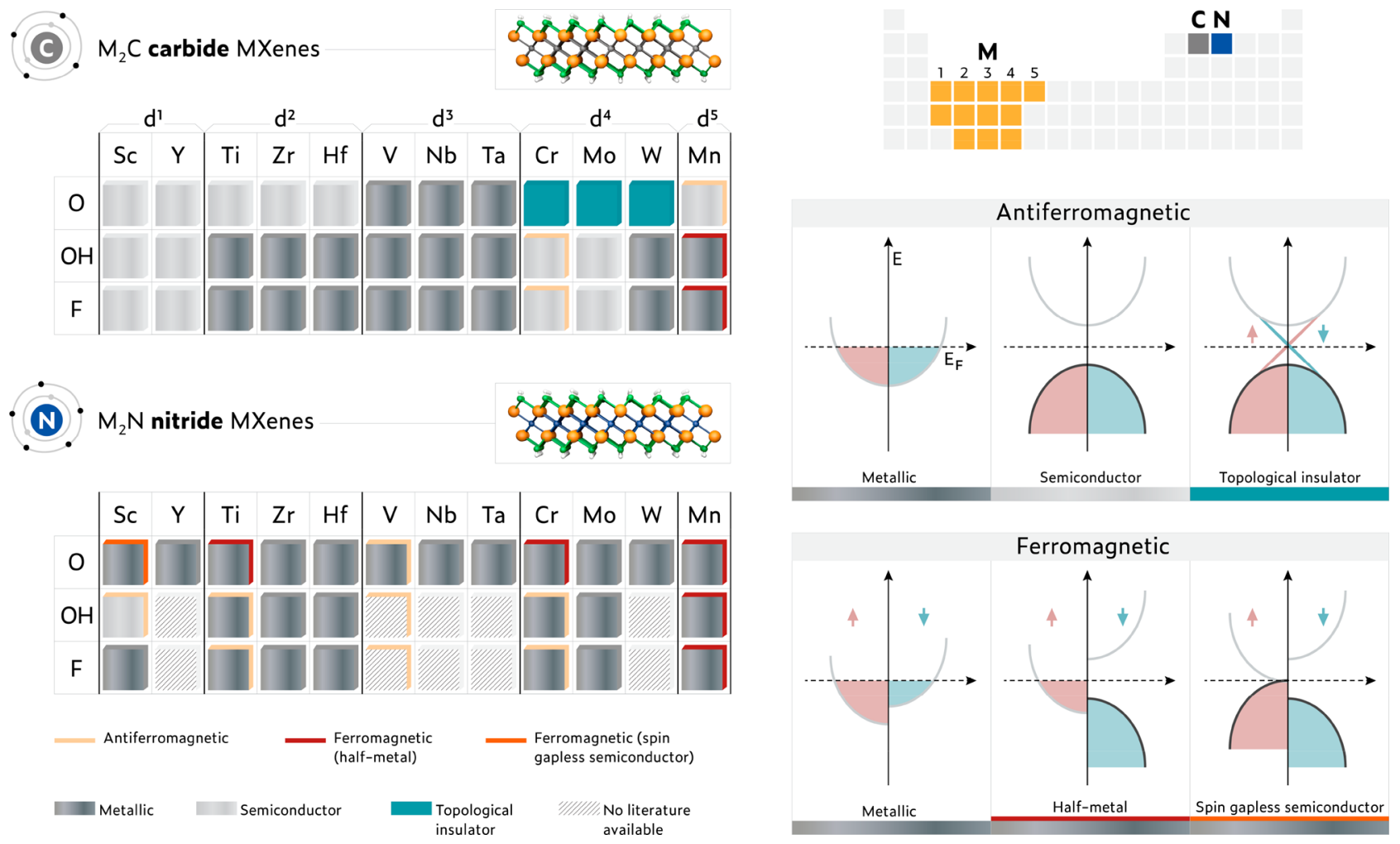

Figure 1. Summary of the theoretically predicted electronic and magnetic properties of $M_{2} C_{x}$ carbide $M$ Xenes and $M_{2} N_{x}$ nitride $M X e n e s$, where $M$ is an early transition-metal element and $T_{x}$ is a surface functional group species $(\mathrm{O}, \mathrm{OH}$, or $\mathrm{F})$. The electronic band structure (metal or semiconductor) and ground-state magnetic configuration (ferromagnetic or antiferromagnetic) are shown. The diverse properties of carbide/nitride MXenes can be tuned by the choice of transition metal and surface functional group. Schematic density of state (DOS) band structures are shown on the right-hand side.

groups, and $\mathrm{X}$ element (carbon and/or nitrogen). For example, the $\mathrm{d}^{1}$ transition metals ( $\mathrm{Sc}$ and $\mathrm{Y}$ ) in carbide MXene are predicted to be semiconductors for any type of full surface termination, while $\mathrm{d}^{2}$ transition metals $(\mathrm{Ti}, \mathrm{Zr}$, and $\mathrm{Hf}$ ) require divalent oxygen termination to have an open band gap. ${ }^{22,23}$ This implies that the number of valence electron in transition metal and the electron-accepting contribution of surface functional groups may offset the free electron density in MXenes, and the strength of hybridization between them affects their band structure. Compare to the carbide MXenes, the nitride MXenes are less promising as semiconductor materials, because of the presence of an additional valence electron in each $\mathrm{N}$ atom; however, they may have promising magnetic properties. Specifically, $\mathrm{Ti}_{2} \mathrm{NO}_{2}, \mathrm{Cr}_{2} \mathrm{NO}_{2}, \mathrm{Mn}_{2} \mathrm{NO}_{2}$, $\mathrm{Mn}_{2} \mathrm{~N}(\mathrm{OH})_{2}$, and $\mathrm{Mn}_{2} \mathrm{NF}_{2}$ MXenes have been predicted to be ferromagnetic half-metals, ${ }^{24,25}$ and the $\mathrm{Sc}_{2} \mathrm{NO}_{2}$ MXene has been predicted to be a ferromagnetic spin gapless semiconductor, ${ }^{26}$ which are promising for spintronic applications. Most of the atomically thicker $\mathrm{M}_{3} \mathrm{X}_{2} \mathrm{~T}_{x}$ and $\mathrm{M}_{4} \mathrm{X}_{3} \mathrm{~T}_{x}$ MXenes have a more complex band structure, because of additional states near the Fermi level; hence, many are predicted to be metallic. Few exceptions can be found from the double transition-metal MXenes listed in Table 1.

Note that experimentally synthesized $\mathrm{Ti}_{2} \mathrm{CT}_{x}$ MXene thin films show metallic behavior. ${ }^{50}$ The difference between theoretical prediction and experimentally obtained results can be attributed to the mixed surface groups, the presence of intercalated $\mathrm{Li}^{+}$cations, and possible defects formed during the synthesis process. The use of $\mathrm{Li}^{+}$cation in $\mathrm{Ti}_{3} \mathrm{C}_{2} \mathrm{~T}_{x}$ MXene synthesis process drastically increases their electrical con- ductivity, compared to classical HF etch route. ${ }^{51}$ In the case of $\mathrm{MoS}_{2}$, intercalation of $\mathrm{Li}^{+}$turns semiconducting $2 \mathrm{H}-\mathrm{MoS}_{2}$ into a metallic $1 \mathrm{~T}-\mathrm{MoS}_{2}$ phase. ${ }^{52}$ The presence of $\mathrm{Li}^{+}$cations results in spontaneous co-intercalation of water molecules between MXene nanosheets via hydrogen bonding and charge interaction. Other intercalated cations, such as $\mathrm{Na}^{+}, \mathrm{K}^{+}, \mathrm{Rb}^{+}$, $\mathrm{Mg}^{2+}$, and $\mathrm{Ca}^{2+}$, were found to modulate the $\mathrm{Ti}_{3} \mathrm{C}_{2} \mathrm{~T}_{x}$ structural response to relative humidity and the degree of hydration; ${ }^{53}$ however, their effects on electronic properties are yet to be explored. Such information could have been missing, because of the highly conductive nature of $\mathrm{Ti}_{3} \mathrm{C}_{2} \mathrm{~T}_{x}$ MXene, where the cation effect was minor. Organic intercalation methods present alternative routes to avoid atomic cations; however, this process results in significantly larger interlayer spacing that hinders inter-flake transport. Organic molecule intercalated MXenes often show semiconducting-like transport behavior, which shows a transition to metal-like behavior upon annealing. ${ }^{54}$ This can be explained based on thermal activation process that overcome the barrier height at the inter-flake contact points with organically intercalated MXene films.

Temperature-dependent resistance measurement of $\mathrm{Ti}_{3} \mathrm{C}_{2} \mathrm{~T}_{x}, \mathrm{Ti}_{3} \mathrm{CNT}_{x}$, and $\mathrm{Mo}_{2} \mathrm{TiC}_{2} \mathrm{~T}_{x}$ by vacuum annealing with electrical biasing revealed these transitions, as shown in Figures $2 a-c .{ }^{54}$ Note that the formal two Ti-based MXenes were prepared via the $\mathrm{HCl}-\mathrm{LiF}$ route, while the latter Mobased MXene was prepared via the HF-TBAOH method. It can be clearly seen that $\mathrm{Li}^{+}$-intercalated MXenes become much conductive after vacuum exposure at RT, while Mo-based MXenes without $\mathrm{Li}^{+}$exhibit no changes. This implies that some portion of weakly bonded absorbent and water molecules 
Table 1. Calculated Value of the Band Gap of Semiconducting MXenes Based on Conventional (PBE) and Hybrid (HSE06) Functionals $^{a}$

\begin{tabular}{|c|c|c|c|c|}
\hline \multirow[b]{2}{*}{ MXene } & \multirow[b]{2}{*}{ termination } & \multicolumn{2}{|c|}{ Band Gap $[\mathrm{eV}]$} & \multirow[b]{2}{*}{ remark $^{b}$} \\
\hline & & $\mathrm{PBE}$ & HSE06 & \\
\hline \multirow[t]{4}{*}{$\mathrm{Sc}_{2} \mathrm{C}$} & $\mathrm{O}$ & $1.78,^{27} 1.8^{22} 1.84,^{28} 1.86^{29,30}$ & $2.87,,^{27} 2.90,,^{26} 2.92,{ }^{31} 3.01^{29}$ & \\
\hline & F & $1.0,{ }^{29,32} 1.01,,^{27} 1.03,,^{22,28,30} 1.05^{33}$ & $1.64,{ }^{33} 1.84,{ }^{26} 1.85,,^{27} 1.88^{29}$ & \\
\hline & $\mathrm{OH}$ & $0.34,,^{29} 0.44,,^{27,28} 0.45,^{22} 0.56,,^{30} 0.71^{32}$ & $0.71,^{29} 0.74,^{26} 0.85^{27}$ & direct band gap \\
\hline & $\mathrm{Cl}$ & $0.88^{26}$ & $1.64^{26}$ & \\
\hline \multirow[t]{3}{*}{$\mathrm{Y}_{2} \mathrm{C}$} & $\mathrm{O}$ & $1.32^{30}$ & & \\
\hline & $\mathrm{F}$ & $1.14^{30}$ & & \\
\hline & $\mathrm{OH}$ & $0.47^{30}$ & & direct band gap \\
\hline $\mathrm{Ti}_{2} \mathrm{C}$ & $\mathrm{O}$ & $0.17,,^{32} 0.24,,^{22,34} 0.26,,^{27} 0.32,^{30} 0.33^{35}$ & $0.78,^{10} 0.88,,^{34} 0.92^{27,36}$ & \\
\hline $\mathrm{Zr}_{2} \mathrm{C}$ & $\mathrm{O}$ & $0.66,^{32} 0.88,^{22} 0.95,,^{35} 0.97^{27,30}$ & $1.54,^{36} 1.70^{27}$ & \\
\hline $\mathrm{Hf}_{2} \mathrm{C}$ & $\mathrm{O}$ & $0.8,^{32} 1.00,^{22,35} 1.02,^{27} 1.03^{30}$ & $1.66,^{27,37} 1.75^{36}$ & \\
\hline \multirow{4}{*}{$\mathrm{Cr}_{2} \mathrm{C}$} & $\mathrm{O}$ & & & TI \\
\hline & $\mathrm{F}$ & $0.22^{32}$ & $3.15,^{38} 3.49^{39}$ & AFM \\
\hline & $\mathrm{OH}$ & $0.03^{32}$ & $1.39,,^{38} 1.43^{39}$ & AFM \\
\hline & $\mathrm{Cl}$ & $0.15^{32}$ & $2.56^{39}$ & AFM \\
\hline \multirow{4}{*}{$\mathrm{Mo}_{2} \mathrm{C}$} & $\mathrm{O}$ & & & TI \\
\hline & $\mathrm{F}$ & $0.25,^{32} 0.30^{27}$ & $0.86^{27}$ & \\
\hline & $\mathrm{OH}$ & $0.1^{32}$ & & \\
\hline & $\mathrm{Cl}$ & $0.15^{32}$ & & \\
\hline $\mathrm{W}_{2} \mathrm{C}$ & $\mathrm{O}$ & $0.194^{40}$ & $0.472^{40}$ & TI \\
\hline $\mathrm{Mn}_{2} \mathrm{C}$ & $\mathrm{O}$ & $0.83^{41}$ & & AFM \\
\hline$\left(\mathrm{Mo}_{2 / 3} \mathrm{Sc}_{1 / 3}\right)_{2} \mathrm{C}$ & $\mathrm{O}$ & $0.04^{42}$ & $0.58^{42}$ & piezoelectric \\
\hline$\left(\mathrm{Mo}_{2 / 3} \mathrm{Y}_{1 / 3}\right)_{2} \mathrm{C}$ & $\mathrm{O}$ & $0.45^{42}$ & $1.23^{42}$ & piezoelectric \\
\hline$\left(\mathrm{W}_{2 / 3} \mathrm{Sc}_{1 / 3}\right)_{2} \mathrm{C}$ & $\mathrm{O}$ & $0.68^{42}$ & $1.3^{42}$ & piezoelectric \\
\hline$\left(\mathrm{W}_{2 / 3} \mathrm{Y}_{1 / 3}\right)_{2} \mathrm{C}$ & $\mathrm{O}$ & $0.63^{42}$ & $1.3^{42}$ & piezoelectric \\
\hline $\mathrm{Mo}_{1.33} \mathrm{C}$ & $\mathrm{O}_{2 / 3} \mathrm{~F}_{1 / 3}$ & $0.5^{43}$ & & \\
\hline $\mathrm{Hf}_{3} \mathrm{C}_{2}$ & $\mathrm{O}$ & & $0.155^{44}$ & \\
\hline \multirow[t]{2}{*}{$\mathrm{Hf}_{2} \mathrm{MnC}_{2}$} & $\mathrm{O}$ & $0.24^{45}$ & & FM \\
\hline & F & $1.03^{45}$ & & AFM \\
\hline $\mathrm{Hf}_{2} \mathrm{VC}_{2}$ & $\mathrm{~F}$ & $0.4^{46}$ & $0.9^{46}$ & multiferroic (type-II) \\
\hline $\mathrm{Mo}_{2} \mathrm{TiC}_{2}$ & $\mathrm{O}$ & $0.04,{ }^{47} 0.05^{48}$ & $0.12,^{47} 0.13^{48}$ & TI \\
\hline $\mathrm{Mo}_{2} \mathrm{ZrC}_{2}$ & $\mathrm{O}$ & $0.07,{ }^{47} 0.09^{48}$ & $0.13,^{47} 0.15^{48}$ & TI \\
\hline $\mathrm{Mo}_{2} \mathrm{HfC}_{2}$ & $\mathrm{O}$ & $0.15,{ }^{47} 0.21^{48}$ & $0.24,^{47} 0.30^{48}$ & TI \\
\hline $\mathrm{W}_{2} \mathrm{TiC}_{2}$ & $\mathrm{O}$ & $0.14^{47}$ & $0.29^{47}$ & TI \\
\hline $\mathrm{W}_{2} \mathrm{ZrC}_{2}$ & $\mathrm{O}$ & $0.17^{47}$ & $0.28^{47}$ & TI \\
\hline $\mathrm{W}_{2} \mathrm{HfC}_{2}$ & $\mathrm{O}$ & $0.29^{47}$ & $0.41^{47}$ & TI \\
\hline \multirow[t]{2}{*}{$\mathrm{Cr}_{2} \mathrm{TiC}_{2}$} & $\mathrm{~F}$ & & $1.35^{38}$ & AFM \\
\hline & $\mathrm{OH}$ & & $0.85^{38}$ & AFM, direct band gap \\
\hline $\mathrm{Sc}_{2} \mathrm{~N}$ & $\mathrm{OH}$ & $3.23^{26}$ & & \\
\hline $\mathrm{Cr}_{2} \mathrm{TiN}_{2}$ & $\mathrm{OH}$ & $0.5^{49}$ & & AFM \\
\hline $\mathrm{Mn}_{2} \mathrm{TiN}_{2}$ & $\mathrm{~F}$ & $1.1^{49}$ & $1.9^{49}$ & AFM \\
\hline
\end{tabular}

${ }^{a_{T}}$ The HSE06 approach is more accurate for band-gap prediction. MXenes with a direct band gap are marked; all others have an indirect band gap. ${ }^{b}$ Certain MXene properties are indicated, such as antiferromagnetic (AFM), ferromagnetic (FM) in their ground state, topological insulator (TI).

were removed under vacuum. Upon vacuum annealing, all three MXenes become more conductive, because of the removal of water, intercalant, and even surface functional groups. $\mathrm{Ti}_{3} \mathrm{C}_{2} \mathrm{~T}_{x}$ retained their metallic behavior (positive $\mathrm{dR}$ / $\mathrm{d} T$ ), while $\mathrm{Ti}_{3} \mathrm{CNT}_{x}$ and $\mathrm{Mo}_{2} \mathrm{TiC}_{2} \mathrm{~T}_{x}$ show semiconductor-like to metallic transition (negative to positive $d R / d T$ ). Figure $2 d$ shows a schematic of the intercalant effects on electrical transport of $\mathrm{Mo}_{2} \mathrm{TiC}_{2} \mathrm{~T}_{x}$ before and after annealing. Three Mobased MXenes $\left(\mathrm{Mo}_{2} \mathrm{CT}_{x}, \mathrm{Mo}_{2} \mathrm{TiC}_{2} \mathrm{~T}_{x}, \mathrm{Mo}_{2} \mathrm{Ti}_{2} \mathrm{C}_{3} \mathrm{~T}_{x}\right)$ synthesized via the $\mathrm{HF}-\mathrm{TBAOH}$ route have shown a similar transition upon annealing under an $\mathrm{Ar} / \mathrm{H}_{2}$ ambient atmosphere (Figure 2e). ${ }^{55}$ The onset temperature of the rapid increase in electrical conductivity was found to be $\sim 220{ }^{\circ} \mathrm{C}$, which is much higher than that measured in an ambient vacuum. Intercalation of either $\mathrm{TMA}^{+}$or $\mathrm{TBA}^{+}$into $\mathrm{Ti}_{3} \mathrm{CNT}_{x}$ has been reported to result in the similar transition from metallic to semiconductorlike behavior. ${ }^{57}$ The interlayer spacing is proportional to the size of organic molecules; hence, the intercalants can engineer the resistance of MXene films. ${ }^{58}$

Recently, an experimental work function modulation of $\mathrm{Ti}_{3} \mathrm{C}_{2} \mathrm{~T}_{x}$ MXene has been reported by in-situ vacuum heating ultraviolet photoelectron spectroscopy (UPS) measurement. ${ }^{56}$ The measured work function of $\mathrm{Ti}_{3} \mathrm{C}_{2} \mathrm{~T}_{x}$ MXene film first gradually increases from $3.9 \mathrm{eV}$ at RT to $4.8 \mathrm{eV}$ at $380{ }^{\circ} \mathrm{C}$, and decreases again to $4.1 \mathrm{eV}$ at $780{ }^{\circ} \mathrm{C}$. (See Figures $2 \mathrm{f}$ and $2 \mathrm{~g}$.) The formal transition is due to the removal of water, $\mathrm{OH}$ groups, and possible contaminants at the low-temperature regime, while the latter transition was attributed to desorption of F-groups at a higher temperature. The thermal behavior of surface termination agrees well with previous reports. ${ }^{60,62}$ Such 

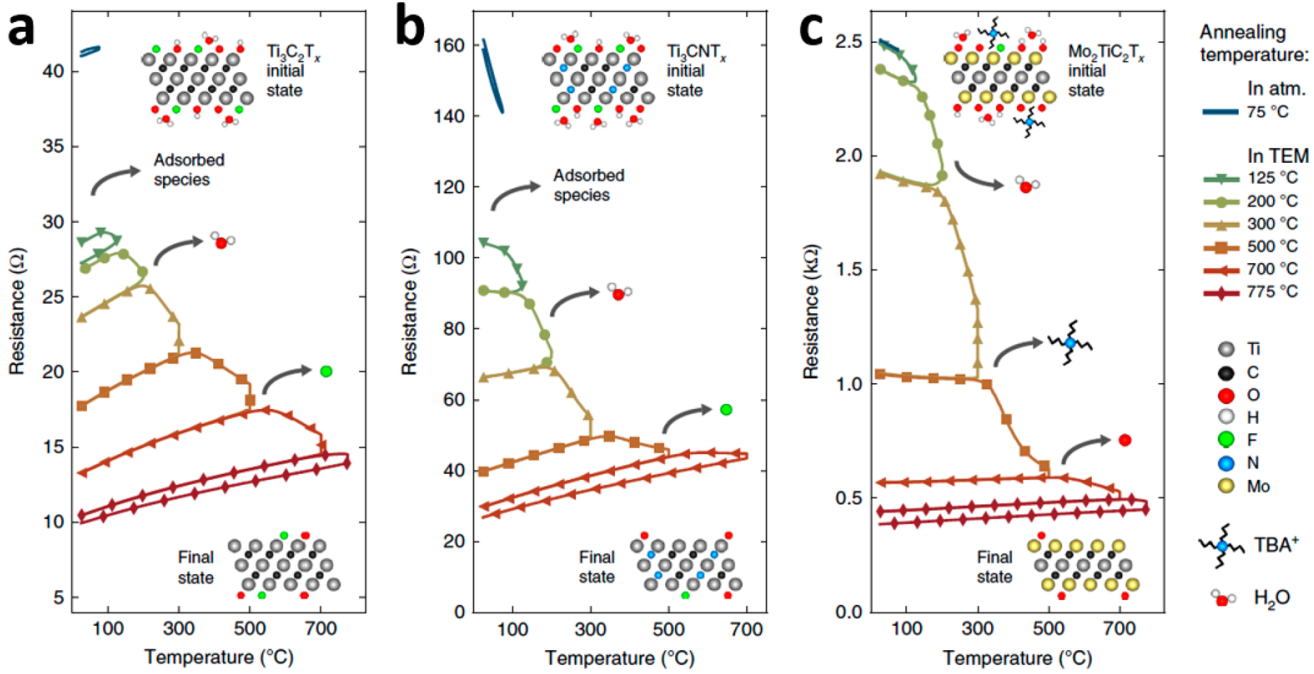

As-prepared (intercalated) $\mathrm{d} R / \mathrm{d} T<0$, semiconductor-like

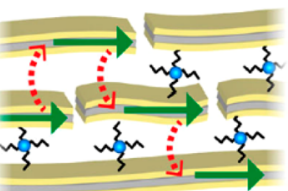

Annealed (de-intercalated) $\mathrm{d} R / \mathrm{d} T>0$, metallic
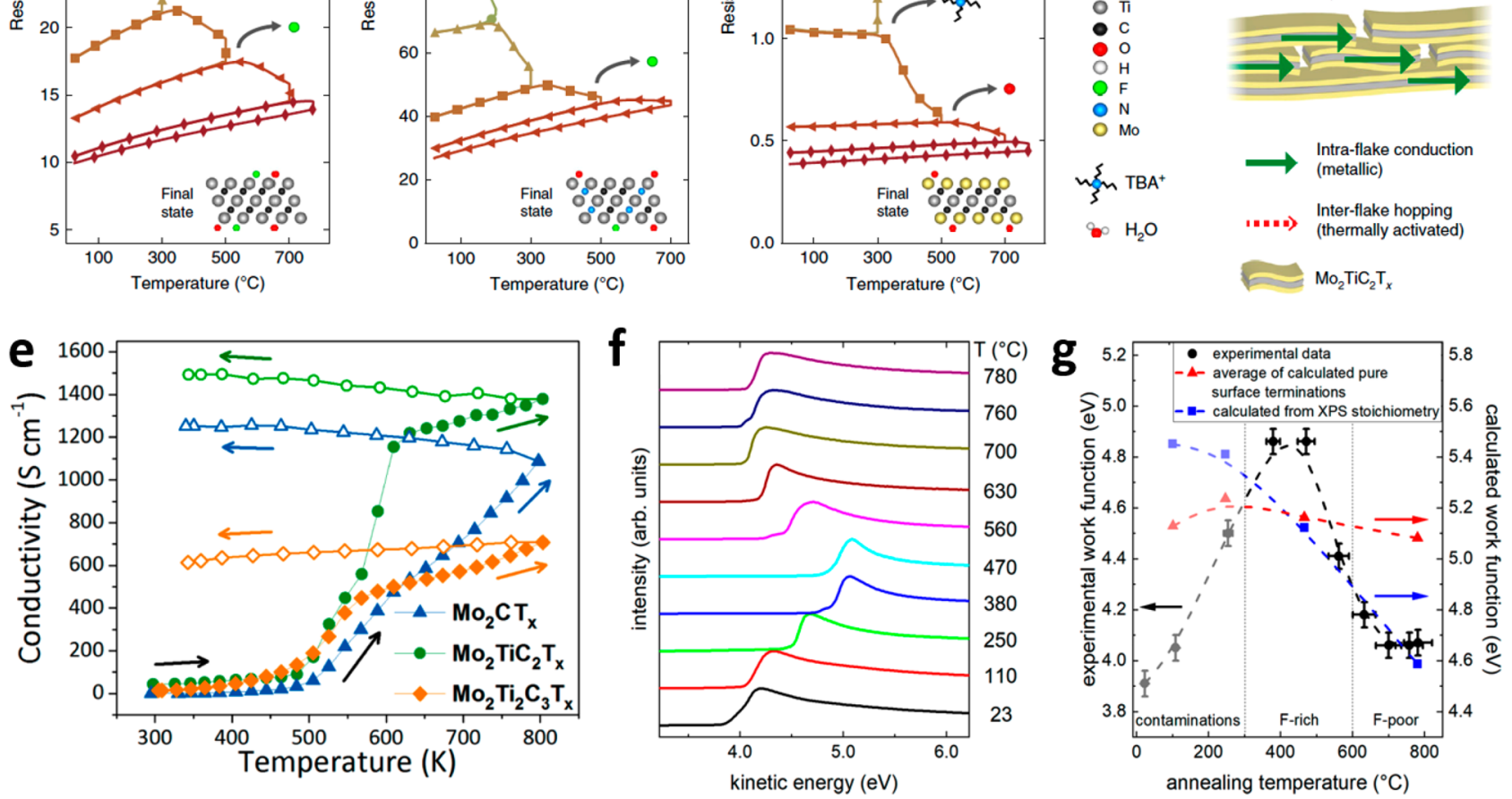

Figure 2. Electrical response of MXene films to thermal treatment. $(a-c)$ Temperature-dependent resistance measurement with in-situ vacuum annealing for $\mathrm{Ti}_{3} \mathrm{C}_{2} \mathrm{~T}_{x}$ (panel (a)), $\mathrm{Ti}_{3} \mathrm{CNT}_{x}$ (panel (b)), and $\mathrm{Mo}_{2} \mathrm{TiC}_{2} \mathrm{~T}_{x}$ MXenes (panel (c)). (d) Schematic illustration of the electrical transport mechanism with and without intercalated organic molecules in $\mathrm{Mo}_{2} \mathrm{TiC}_{2} \mathrm{~T}_{x} \mathrm{MXene}$. [Reproduced, with permission, from ref 54, under the Creative Commons Attribution 4.0 International License (CC BY 4.0). Copyright 2019, Springer Nature.] (e) Temperature-dependent electrical conductivity of $\mathrm{TBA}^{+}$intercalated Mo-based MXenes under $\mathrm{Ar} / \mathrm{H}_{2}$ ambient. [Reproduced, with permission, from ref 55. Copyright 2017, American Chemical Society, Washington, DC.] (f) Ultraviolet photoelectron spectroscopy (UPS) spectra of $\mathrm{Ti}_{3} \mathrm{C}_{2} \mathrm{~T}_{x}$ MXene with vacuum anneal treatments. $(\mathrm{g})$ Experimentally measured and calculated work functions of $\mathrm{Ti}_{3} \mathrm{C}_{2} \mathrm{~T}_{x} \mathrm{MXene}$ as a function of vacuum annealing temperature. [Reproduced, with permission, from ref 56. Copyright 2019, American Chemical Society, Washington, DC.]

modulations in work function are particularly critical to achieving MXene-contacted electronics. For example, $\mathrm{Ti}_{3} \mathrm{C}_{2} \mathrm{~T}_{x}$ MXene has been used in contact electrodes for $n$ type $\mathrm{ZnO}$ and $p$-type $\mathrm{SnO}$ channel TFTs, as well as gate electrode, achieving a high-performance CMOS inverter (see Figures $3 \mathrm{a}-\mathrm{d}) .{ }^{59}$ In addition, $\mathrm{Ti}_{2} \mathrm{CT}_{x}$ MXene has recently been used as contacts in transistors with $\mathrm{MoS}_{2}, \mathrm{WSe}_{2}{ }^{63}$ and Pentacene. $^{64}$

The metallic conductivity of $\mathrm{Ti}_{3} \mathrm{C}_{2} \mathrm{~T}_{x}$ MXene films originates from the high free electron density in each nanosheet, and from the highly aligned structure of restacked nanosheet films providing a sufficient number of electrical paths. An ellipsometry study revealed that the real part of the dielectric constant of $\mathrm{Ti}_{3} \mathrm{C}_{2} \mathrm{~T}_{x}$ changes from positive to negative at wavelengths larger than $1130 \mathrm{~nm}$, implying the onset of plasmonic responses. ${ }^{65}$ Intense surface plasmons have been experimentally confirmed using the high-resolution electron energy loss spectroscopy (EELS) technique. ${ }^{66}$ More importantly, the surface plasmon energies can be tuned by MXene's shape, size, thickness, and surface groups that can cover a wide range of frequencies (from mid-infrared to terahertz frequencies). ${ }^{60,66}$ Figure $3 \mathrm{e}$ shows the visualized surface plasmon modes in the $\mathrm{Ti}_{3} \mathrm{C}_{2} \mathrm{~T}_{x}$ flake. Note that these plasmonic responses in each nanosheet remain in multilayer MXene as isolated islands, suggesting high potential in optical communication and chemical sensing applications. ${ }^{60}$

Nanoindentation study on a suspended monolayer $\mathrm{Ti}_{3} \mathrm{C}_{2} \mathrm{~T}_{x}$ MXene has revealed their effective Young's modulus of 330 $\mathrm{GPa}$, which is higher than that of other solution-processed 2D materials, ${ }^{67}$ suggesting the potential use of MXene as multifunctional filler in composites. For example, a significantly enhanced dielectric constant was found in $\mathrm{Ti}_{3} \mathrm{C}_{2} \mathrm{~T}_{x}$ MXene/ poly(vinylidene fluoride-trifluoro-ethylene-chlorofluoroethylene) ( $\mathrm{P}[\mathrm{VDF}-\mathrm{TrFE}-\mathrm{CFE}])$ polymer composite (see Figures $3 \mathrm{f}-\mathrm{h}) .{ }^{61}$ The largest enhancement was found near the percolation limit of 15.0 wt $\%$ MXene loading. $\mathrm{Ti}_{3} \mathrm{C}_{2} \mathrm{~T}_{x}$ MXene-based PVA hydrogel shows unique asymmetrical strain sensitivity with highly stretchable and self-healing ability (Figures $3 \mathbf{i}$ and $3 \mathbf{j})$. ${ }^{\text {is }}$

Given the above mentioned unique properties of MXenes and their large potential, we highlight the recent advances in MXetronics, which is a fast-emerging field of MXene 
a

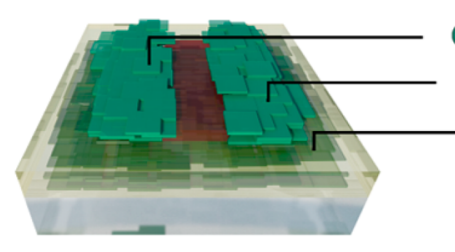

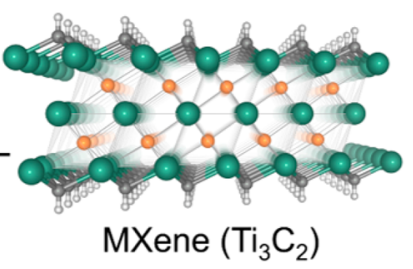

MXene $\left(\mathrm{Ti}_{3} \mathrm{C}_{2}\right)$
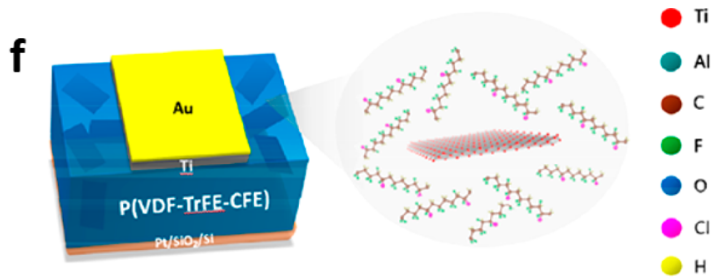
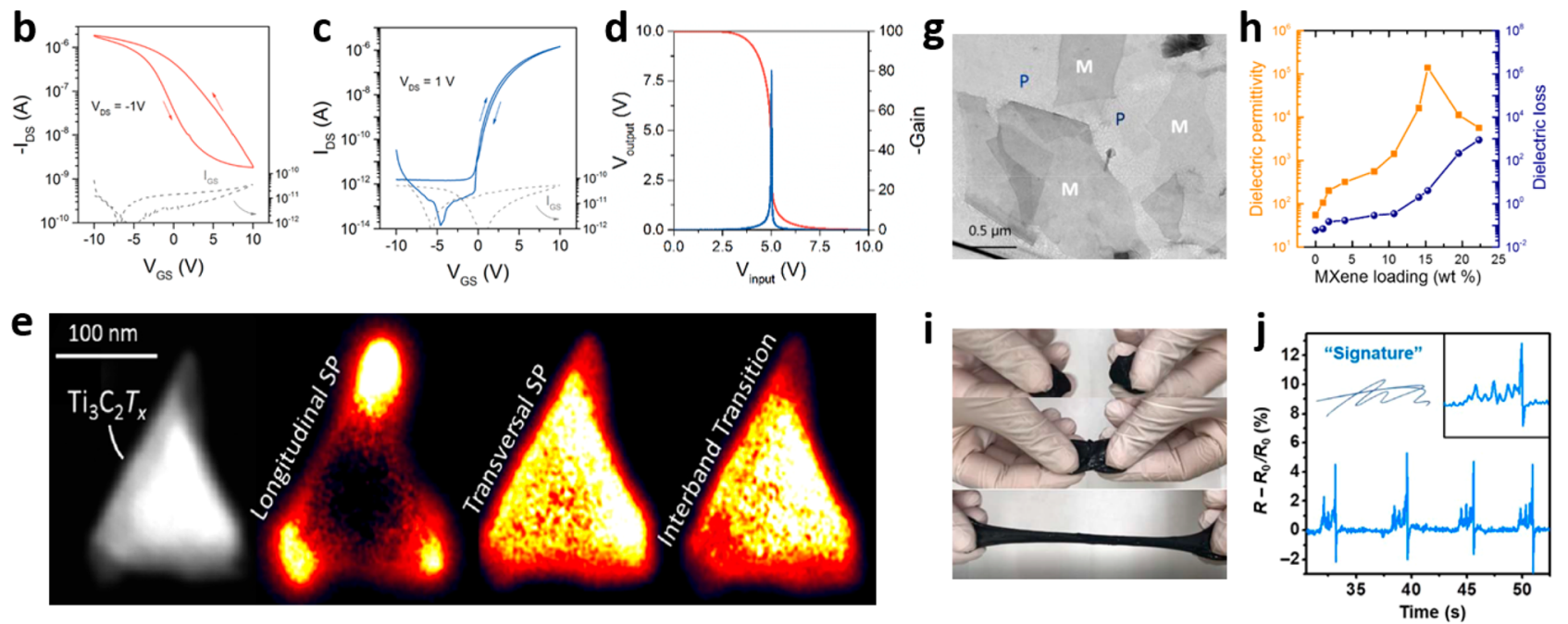

Figure 3. (a) Schematic illustration of all-MXene contacted oxide TFTs. (b, c) Transfer characteristics of $p$-type SnO TFT (panel (b)) and $n$ type $\mathrm{ZnO}$ TFT (panel (c)), using $\mathrm{Ti}_{3} \mathrm{C}_{2} \mathrm{~T}_{x}$ MXene films for source, drain, and gate electrodes. (d) Voltage transfer curve of a MXenecontacted CMOS inverter. [Reproduced, with permission, from ref 59. Copyright 2018, Wiley-VCH Verlag GmbH \& Co. KGaA, Weinheim, Germany]. (e) High-angle annular dark-field scanning transmission electron microscopy (STEM-HAADF) image of $\mathrm{Ti}_{3} \mathrm{C}_{2} \mathrm{~T}_{x} \mathrm{MXene}$ flake with corresponding EELS fitted intensity mapping for different surface plasmonic modes. [Reproduced, with permission, from ref 60. Copyright 2018, American Chemical Society, Washington, DC.] (f) Schematic of a capacitor device using $\mathrm{Ti}_{3} \mathrm{C}_{2} \mathrm{~T}_{x} \mathrm{MXene} / \mathrm{P}(\mathrm{VDF}-\mathrm{TrFE}-$ CFE) polymer composite as the dielectric. ( $g$ ) TEM image showing individual $\mathrm{Ti}_{3} \mathrm{C}_{2} \mathrm{~T}_{x}$ MXene flakes in the host polymer. (h) Dielectric permittivity and dielectric loss, as a function of MXene loading. The largest enhancement was found at the percolation limit of MXene loading ( 15 wt \%). [Reproduced, with permission, from ref 61. Copyright 2018, American Chemical Society, Washington, DC.] (i) Photography of $\mathrm{Ti}_{3} \mathrm{C}_{2} \mathrm{~T}_{x}$ MXene/PVA hydrogel composite, showing self-healing ability and stretchability. (j) Resistance changes of MXene hydrogel sensor upon repeated signature motion. [Reproduced with permission under the Creative Common Attribution NonCommercial 4.0 International License (CC BY-NC 4.0). ${ }^{15}$ Copyright 2018, American Association for the Advancement of Science (AAAS).]

research. ${ }^{17}$ Electronic applications of MXene such as low-cost solution-processable electrical contact material for organic thin-film transistors (OTFTs), ${ }^{68}$ silicon/perovskite solar cells, ${ }^{69-71}$ charge trapping filler in polymer-based memory device, $^{72}$ and gas sensors, ${ }^{14,73,74}$ as well as photonic applications including unusual plasmonic photodetection, ${ }^{75}$ and photoluminescent MXene quantum dots, ${ }^{76,77}$ are discussed. MXenes have also been utilized as growth template for van der Waals epitaxy growth, ${ }^{78}$ and their hydrothermal conversion has realized robust ferroelectric single crystals with surprisingly high aspect-ratio morphology. ${ }^{79}$

\section{ELECTRONIC APPLICATIONS OF MXENES}

Organic thin-film transistors (OTFTs) and complementary logic circuits have recently been demonstrated using $\mathrm{Ti}_{3} \mathrm{C}_{2} \mathrm{~T}_{x}$ MXene as contact electrodes, with $p$-type Pentacene and $n$ type $N, N$-dioctyl-3,4,9,10-perylenedicarboximide (PTCDI- $C_{8}$ ) channels (see Figure 4). ${ }^{68}$ A thin layer of cross-linked poly(4vinylphenol) (cPVP) was first coated on flexible poly(ethylene 2,6-naphthalate) (PEN) substrates, followed by UV/ozone treatment through a shadow mask. The created hydrophilic/ hydrophobic patterns allow selective wetting of aqueous $\mathrm{Ti}_{3} \mathrm{C}_{2} \mathrm{~T}_{x}$ MXene dispersion that forms patterned MXene electrodes array after drying. This process was repeated on the top of a thicker cPVP dielectric layer for the top MXene contact electrodes. The organic channels were deposited via a thermal evaporation method through shadow masks. The work function of $\mathrm{Ti}_{3} \mathrm{C}_{2} \mathrm{~T}_{x}$ was found to be $4.9 \mathrm{eV}$ by Kelvin probe force microscopy (KPFM). This value is suitable for $p$-type Pentacene with a highest occupied molecular orbit (HOMO) level of $5.0 \mathrm{eV}$. However, pristine $\mathrm{Ti}_{3} \mathrm{C}_{2} \mathrm{~T}_{x}$ was not suitable for $n$-type PTCDI- $\mathrm{C}_{8}$ with their lowest unoccupied molecular level (LUMO) of $4.3 \mathrm{eV}$. The work function of $\mathrm{Ti}_{3} \mathrm{C}_{2} \mathrm{~T}_{x}$ MXene was effectively modulated to $4.4 \mathrm{eV}$ by $\mathrm{NH}_{3}$ doping. Both $p$ - and $n$ type OTFTs with proper MXene contacts show great device performance, such as maximum carrier mobility of $\sim 1 \mathrm{~cm}^{2} \mathrm{~V}^{-1}$ $\mathrm{s}^{-1}$ and on/off current ratio of $\sim 10^{7}$. NOT, NAND, and NOR logic circuits were also demonstrated by the integration of $p$ and $n$-type OTFTs.

$\mathrm{Ti}_{3} \mathrm{C}_{2} \mathrm{~T}_{x}$ MXene-contacted $\mathrm{Si}$ solar cells have been demonstrated with a maximum power conversion efficiency (PCE) of $\sim 11.5 \%$ under AM1.5G illumination (see Figures $5 \mathrm{a}-\mathrm{c}) .{ }^{69}$ Delaminated MXene solution was simply drop-casted on the groove surface of $n^{+}$-Si surface in $n^{+}-n-p^{+}$Si solar cell. Rapid thermal annealing (RTA) treatment was adopted to improve electrical contact under an ambient Ar atmosphere for $30 \mathrm{~s}$. It was also found that RTA treatment enhances the physical adhesion of MXene with the substrates. The work function of $\mathrm{Ti}_{3} \mathrm{C}_{2} \mathrm{~T}_{x}$ MXene was found to be $4.28 \mathrm{eV}$, which, interestingly, was not affected by short RTA process. An ohmic 

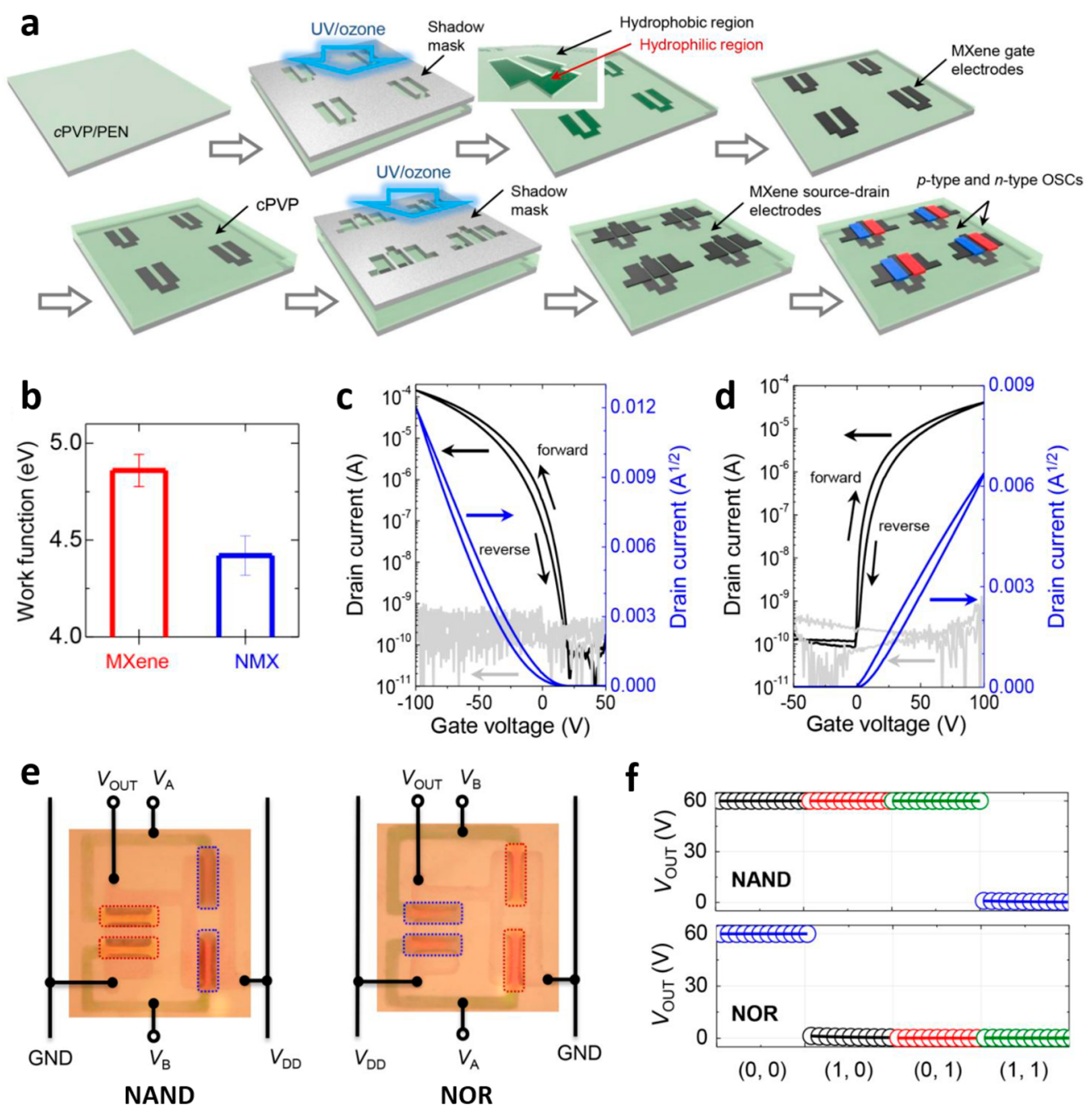

Figure 4. $\mathrm{Ti}_{3} \mathrm{C}_{2} \mathrm{~T}_{x}$ MXene contacted OTFTs and logic gates. (a) Schematic illustration of the device fabrication process. (b) Work function of MXene and $\mathrm{NH}_{3}$-treated MXene (NMX). (c, d) Transfer characteristics of $p$-type Pentacene OTFT, using pristine MXene contact (panel (c)), and $n$-type PTCDI-C 8 OTFT using $\mathrm{NH}_{3}$-treated MXene contact (panel (d)). (e, f) Optical photograph (panel (e)) and output voltages (panel (f)) of NAND and NOR gates. Blue and red rectangles are used to mark $\boldsymbol{p}$-type and $n$-type organic channel areas, respectively. [Reproduced, with permission, from ref 68. Copyright 2019, American Chemical Society, Washington, DC.]

contact was formed between MXene film and the heavily doped $n^{+}-\mathrm{Si}$, along with suppressed charge carrier recombination, resulting in improved fill factor and overall PCE.

In another approach, $\mathrm{Ti}_{3} \mathrm{C}_{2} \mathrm{~T}_{x}$ MXene was directly deposited on $n$-Si substrate to form Schottky junction heterostructures for self-driven photodetectors, ${ }^{80}$ and a new type of solar cell with an average PCE of $10.2 \%$ (see Figures $5 \mathrm{~d}-\mathrm{g}$ ). ${ }^{70}$ The latter photovoltaic study revealed that the existence of a thin $\mathrm{SiO}_{2}$ layer between $\mathrm{Ti}_{3} \mathrm{C}_{2} \mathrm{~T}_{x}$ MXene and $n$-Si is critical to achieving effective separation of photogenerated electron-hole pairs. A two-step chemical treatment using $\mathrm{HCl}$ and $\mathrm{AuCl}_{3}$ was adopted to enhance the electrical conductivity and Schottky barrier height, respectively. The work function of MXene remained in the range of $4.8-4.9 \mathrm{eV}$. The chemical treatment using $\mathrm{AuCl}_{3}$ also resulted in the formation of gold nanoparticles that improved the charge transfer properties of the heterostructure. Such enhancement could be affected by the plasmonic effect of gold nanoparticle, which was previously reported for surface-enhanced Raman spectroscopy application of MXene using a similar precursor, namely, $\mathrm{HAuCl}_{4}{ }^{81}$ The Schottky metal-semiconductor contact is also desirable in metal-semiconductor-metal planar photodetectors, as demon- strated in a recent study of gallium arsenide (GaAs) photodetector, where $\mathrm{Ti}_{3} \mathrm{C}_{2} \mathrm{~T}_{x}$ MXene-contacted devices outperformed the standard $\mathrm{Ti} / \mathrm{Au}$-contacted device. ${ }^{82}$

Recently, $\mathrm{Ti}_{3} \mathrm{C}_{2} \mathrm{~T}_{x}$ MXene has been utilized in perovskite solar cells for work function and interface engineering, resulting in a remarkable enhancement in PCE of $26.5 \%$ over the reference device without MXene (PCE from $~ 15 \%$ to $19 \%$, on average).$^{71}$ Once a small amount of MXene is doped into the perovskite precursor solution, the work function of resulting perovskite film was effectively shifted from $4.72 \mathrm{eV}$ to $4.37 \mathrm{eV}$ without affecting other intrinsic properties such as band gap, the relative position of valence band to Fermi level or the film morphology. A similar work function tuning effect has been observed in solution processed $\mathrm{TiO}_{2}$ electron transfer layer that is fine-tuned from $3.91 \mathrm{eV}$ to $3.85 \mathrm{eV}$ by MXene doping. The MXene-doped $\mathrm{TiO}_{2}$ layer was subject to a thermal annealing at $480{ }^{\circ} \mathrm{C}$ in air, resulting in partial oxidation of MXene. Such work function engineering in a multilayered perovskite enabled enhanced overall solar cell performance by adjusting band alignment. In addition to the MXene doping, a thin layer of conductive MXene film was deposited to engineer the interface between perovskite absorber and $\mathrm{TiO}_{2}$ electron 
a

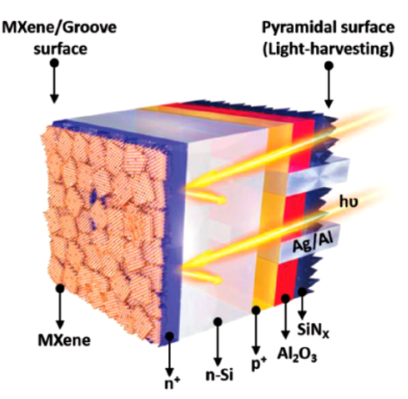

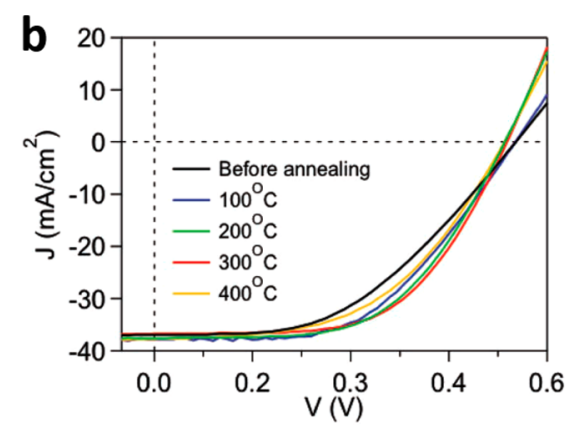
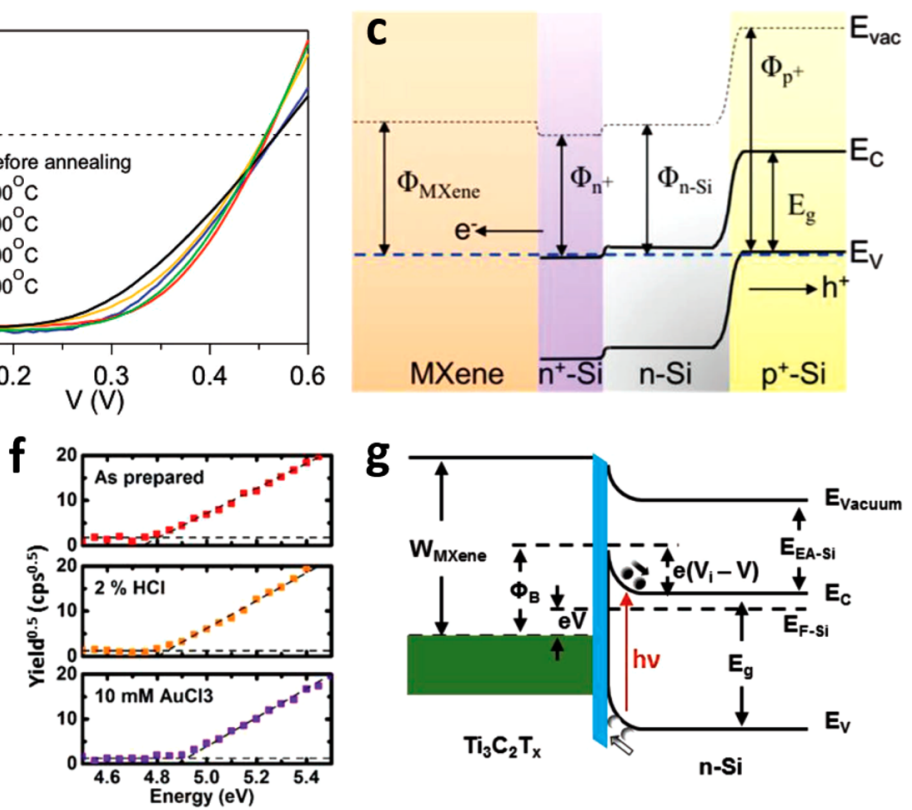
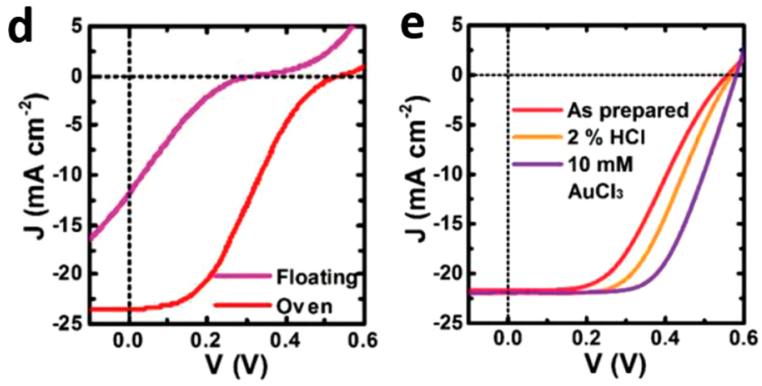

Figure 5. (a) Schematic illustration of $\mathrm{Ti}_{3} \mathrm{C}_{2} \mathrm{~T}_{x}$ MXene contacted $n^{+}-p-p^{+} \mathrm{Si}$ solar cell. (b) Current density-voltage characteristics of $\mathrm{Ti}_{3} \mathrm{C}_{2} \mathrm{~T}_{x}$ MXene $/ n^{+}-p-p^{+} \mathrm{Si}$ solar cell under illumination, before and after rapid thermal annealing (RTA) treatment from $100{ }^{\circ} \mathrm{C}$ to $400{ }^{\circ} \mathrm{C}$. (c) Proposed band diagram of $\mathrm{Ti}_{3} \mathrm{C}_{2} \mathrm{~T}_{x}$ MXene contacted $n^{+}-p-p^{+} \mathrm{Si}$ solar cell. [Reproduced, with permission, from ref 69. Copyright 2019, Wiley-VCH Verlag GmbH \& Co. KGaA, Weinheim, Germany.] (d) $J-V$ characteristics of $\mathrm{Ti}_{3} \mathrm{C}_{2} \mathrm{~T}_{x} \mathrm{MXene} / n$-Si under illumination, with and without a thin $\mathrm{SiO}_{2}$ layer (oven and floating methods, respectively) (e) $J-V$ characteristics of $\mathrm{Ti}_{3} \mathrm{C}_{2} \mathrm{~T}_{x} \mathrm{MXene}_{\mathrm{S}} / \mathrm{SiO} / n$-Si under illumination, before and after chemical treatments using $\mathrm{HCl}$ and $\mathrm{AuCl}_{3}$. (f) Photoelectron spectroscopy in air (PESA) spectra of $\mathrm{Ti}_{3} \mathrm{C}_{2} \mathrm{~T}_{x} \mathrm{MXene}$, before and after chemical treatments. (g) Proposed band diagram of $\mathrm{Ti}_{3} \mathrm{C}_{2} \mathrm{~T}_{x} \mathrm{MXene} / \mathrm{SiO} / n$-Si solar cell. [Reproduced, with permission, from ref 70. Copyright 2019, Wiley-VCH Verlag GmbH \& Co. KGaA, Weinheim, Germany.]

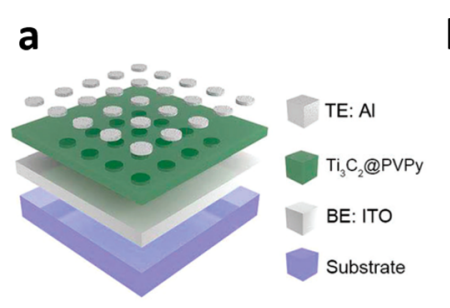

e
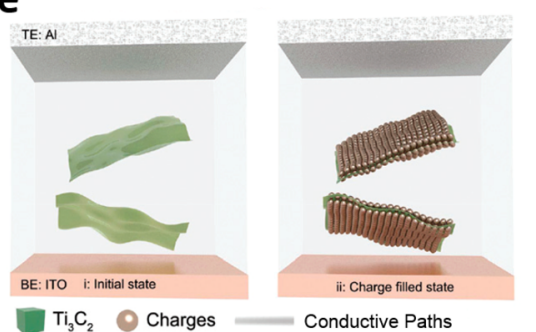
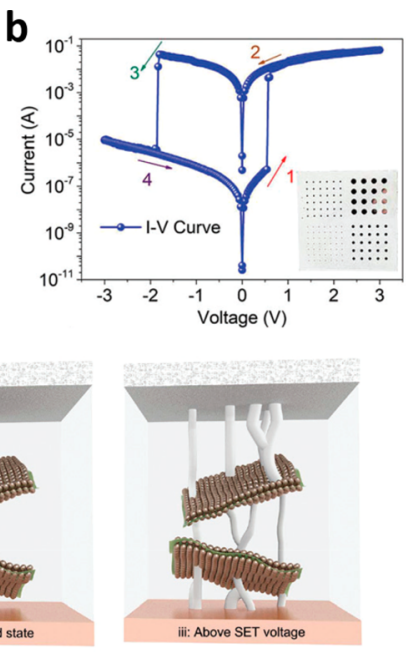
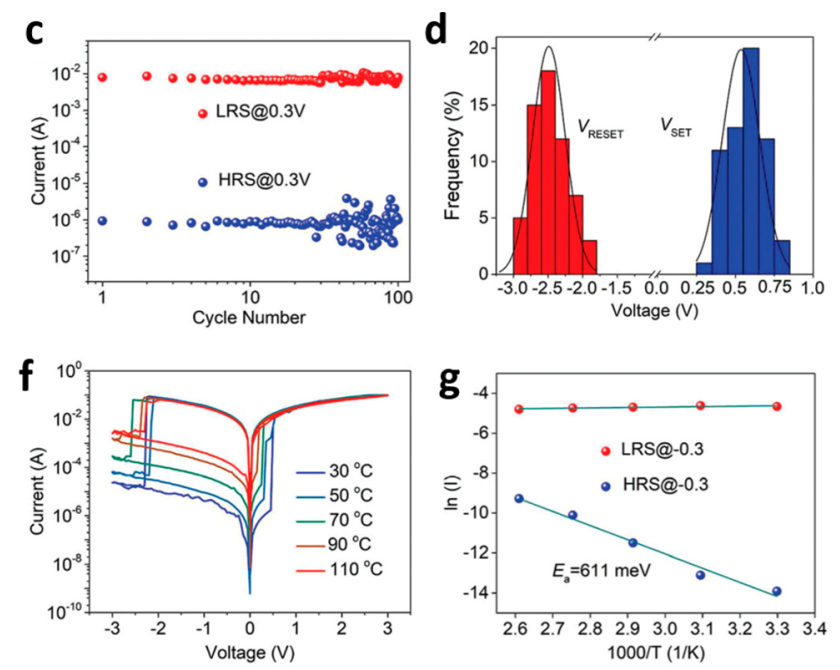

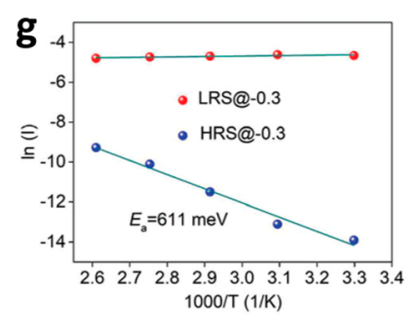

Figure 6. $\mathrm{Ti}_{3} \mathrm{C}_{2} \mathrm{~T}_{x}$ MXene@PVP polymer-composite-based RRAM device. (a) Schematic illustration of MIM structured RRAM device. (b) Bipolar current-voltage characteristics. (c) Endurance characteristics. (d) Statistic distribution of SET and RESET voltage. (e) Schematic illustration of the resistive switching mechanism. (f) Device characteristics under different temperature. (g) Temperature dependence of current in high resistance state (HRS) and low resistance state (LRS). [Reproduced, with permission, from ref 72. Copyright 2019, The Royal Society of Chemistry, London.]

transfer layer. This thin $\mathrm{Ti}_{3} \mathrm{C}_{2} \mathrm{~T}_{x}$ MXene layer could further tune the band alignment of perovskite $/ \mathrm{TiO}_{2}$ interface by charge-transfer-induced interface dipole. Moreover, the MXene interlayer reduces the barrier height at the perovskite $/ \mathrm{TiO}_{2}$ interface and improves open-circuit voltage $\left(V_{\text {oc }}\right)$. Each MXene adopted process contributes incremental increase in overall solar cell performances, and the best device shows a remarkable PCE of $20.14 \%$ with a fill factor of $77.6 \%$, a short-circuit current density of $23.82 \mathrm{~mA} \mathrm{~cm}^{-1}$, and an opencircuit voltage of $1.09 \mathrm{~V}$. The MXene-doped device also exhibits a reduced charge trapping efficiency, evidenced by reduced hysteresis in $J-V$ curve and enhanced long-time exposure stability of the solar cell. The optimized MXene doping amount in the perovskite precursor solution was 0.014 $\mathrm{mg} \mathrm{mL}^{-1}$. 

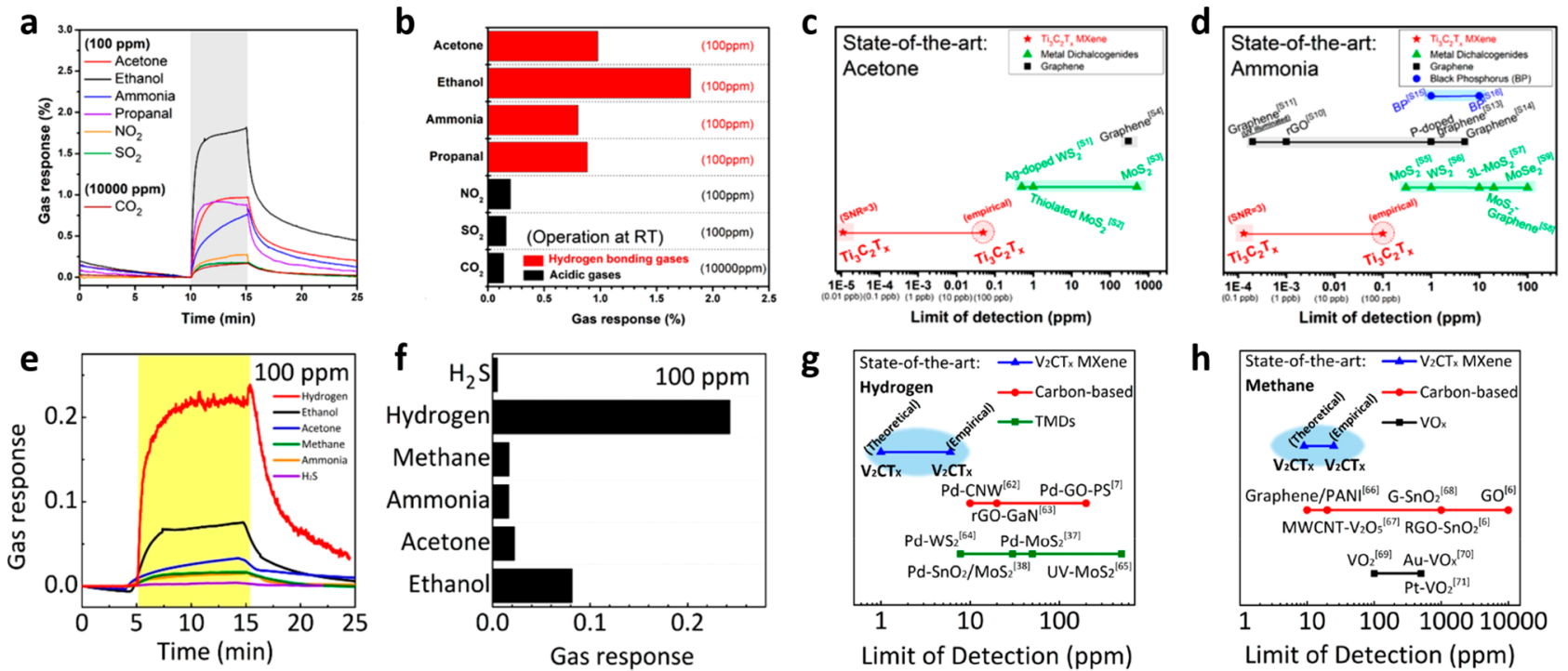

Figure 7. (a-d) $\mathrm{Ti}_{3} \mathrm{C}_{2} \mathrm{~T}_{x}$ MXene gas sensor. (a) Resistance variation upon exposure to $100 \mathrm{ppm}$ of acetone, ethanol, ammonia, propanol, $\mathrm{NO}_{2}, \mathrm{SO}_{2}$, and $10000 \mathrm{ppm}$ of $\mathrm{CO}_{2}$ at RT. (b) Summary of maximum response to the target analytes. (c, d) Comparison of the limit of detection with 2D-material-based sensors at RT for acetone (panel (c)) and ammonia (panel (d)). [Reproduced, with permission, from ref 14. Copyright 2018, American Chemical Society, Washington, DC.] (e, f) $\mathrm{V}_{2} \mathrm{CT}_{x}$ MXene gas sensor, showing resistance variation upon exposure to $100 \mathrm{ppm}$ of hydrogen, ethanol, acetone, methane, ammonia, and $\mathrm{H}_{2} \mathrm{~S}$ at RT (panel (e)), and a summary of the maximum response (panel $(\mathrm{f})) .(\mathrm{g}, \mathrm{h})$ Comparison of the limit of detection with other carbon- and vanadium-based materials at RT for hydrogen (panel $(\mathrm{g})$ ) and methane (panel (h)). [Reproduced, with permission, from ref 73. Copyright 2019, American Chemical Society, Washington, DC.]

$\mathrm{Ti}_{3} \mathrm{C}_{2} \mathrm{~T}_{x}$ MXene-based nonvolatile resistive random access memory (RRAM) has been developed in PVP composite films (Figure 6). ${ }^{72}$ The RRAM device was constructed in a metalinsulator-metal (MIM) sandwich structure (ITO/ $\mathrm{Ti}_{3} \mathrm{C}_{2} \mathrm{~T}_{x} @$ $\mathrm{PVP} / \mathrm{Al}$, from bottom to top) on the PEN substrate. The MXene-based RRAM devices show typical bipolar resistive switching behavior with excellent characteristics, such as a high ON/OFF ratio of $10^{4}$ and a long retention time of $5 \times 10^{4} \mathrm{~s}$. Few-atomic-layer-thick MXene allowed a low SET voltage of $\sim 0.5 \mathrm{~V}$, which is highly dependent on the MXene concentration in the composites. The larger amount of MXene results in a decrease in the spacing between the MXene sheets; hence, the formation of conductive paths becomes easier at a lower SET voltage. In contrast, RESET voltage increases due to the shorter distance between MXene, hindering the rupture of the conductive paths. The existence of surface functional groups in MXene plays a critical role for charge trapping and constructing conductive paths. Moreover, multilevel data storage could be achieved by adjusting the compliance current. In this study, MXene@PVP composite devices operate without electroforming, and the control devices made of either pure MXene or pure PVP layer does not show resistive switching behavior.

Another $\mathrm{Ti}_{3} \mathrm{C}_{2} \mathrm{~T}_{x}$ MXene-based memristor device has been reported for their use in artificial bio-synapse applications. ${ }^{83}$ After the electroforming process, $\mathrm{Pt} / \mathrm{Ti}_{3} \mathrm{C}_{2} \mathrm{~T}_{x} / \mathrm{Al}$ (from bottom to top) devices show bipolar resistive switching behavior and nonvolatile memory effect. More importantly, the resistance of the device could be modulated by minimum pulsed-voltage durations of only $10 \mathrm{~ns}$, which is faster than that reported in literature reports. The repeated pulsed voltage signal results in a transition from short-term plasticity to long-term plasticity, which mimics the synaptic plasticity of the human brain. The formation of oxygen vacancies was proposed to be the cause of the low resistivity state under pulsed voltages, along with the change in the oxidation state of titanium, from $\mathrm{Ti}^{4+}$ to $\mathrm{Ti}^{3+}$, to achieve charge balance.

Metallic $\mathrm{Ti}_{3} \mathrm{C}_{2} \mathrm{~T}_{x}$ MXene has been utilized as a gas-sensing channel for the detection of volatile organic compounds (VOCs) at the parts per billion (ppb) level (see Figures $7 \mathrm{a}-$ d). ${ }^{14}$ An ultrahigh signal-to-noise ratio (SNR) was achieved due to the low noise of metallic $\mathrm{Ti}_{3} \mathrm{C}_{2} \mathrm{~T}_{x}$ MXene and the strong signal of the fully functionalized surface of MXenes. Furthermore, high sensitivity was found especially for hydrogen-bonding gases, implying rich surface interaction between the gas molecules and the surface terminations. Metallic $\mathrm{Ti}_{3} \mathrm{C}_{2} \mathrm{~T}_{x}$ MXene shows a unique gas sensing mechanism where the resistance increases upon exposure of both oxidizing- and reducing-type gases, unlike typical semiconductor sensors involving electron donation/acceptance. The empirical limit of detection of $\sim 50 \mathrm{ppb}$ for acetone, and $\sim 100 \mathrm{ppb}$ for ethanol and ammonia at RT. Because of the ultra-high SNR that is 2 orders of magnitude higher than other $2 \mathrm{D}$ materials, the theoretically available limit of detection of $\mathrm{Ti}_{3} \mathrm{C}_{2} \mathrm{~T}_{x}$ MXene is estimated to be in the sub-ppm level for SNR of 3 .

Recently, $\mathrm{V}_{2} \mathrm{CT}_{x}$ MXene-based gas sensor has been reported for their high sensitivity toward nonpolar gases (see Figures $7 \mathrm{e}-\mathrm{h}) .{ }^{73} \mathrm{~V}_{2} \mathrm{CT}_{x}$ MXene shows effective detection of hydrogen gas, where their gas response is three times higher than that of ethanol at $100 \mathrm{ppm}$ at RT. The theoretical limit of detection for hydrogen and methane was estimated to be 1.3 and 25 ppm, respectively, for $\mathrm{SNR}=3$. The sensing mechanism toward inert nonpolar gases is not clearly known yet. The gas sensing behavior of $\mathrm{V}_{2} \mathrm{CT}_{x}$ MXene is clearly different from that observed for previously studied $\mathrm{Ti}_{3} \mathrm{C}_{2} \mathrm{~T}_{x}$ MXene by the same group. ${ }^{84}$ This suggests the large family of MXenes as potentially promising gas sensing platform with a wide range of gas-selectivity and tunability. The roles of transition-metal species and the population of surface functional groups for 
a

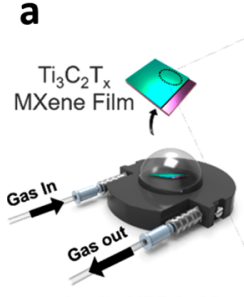

In situ XRD holder
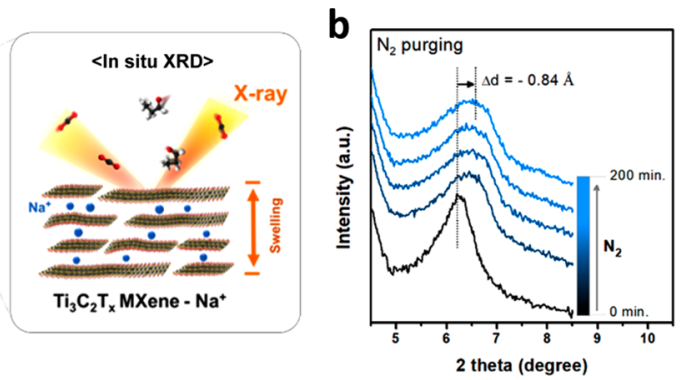
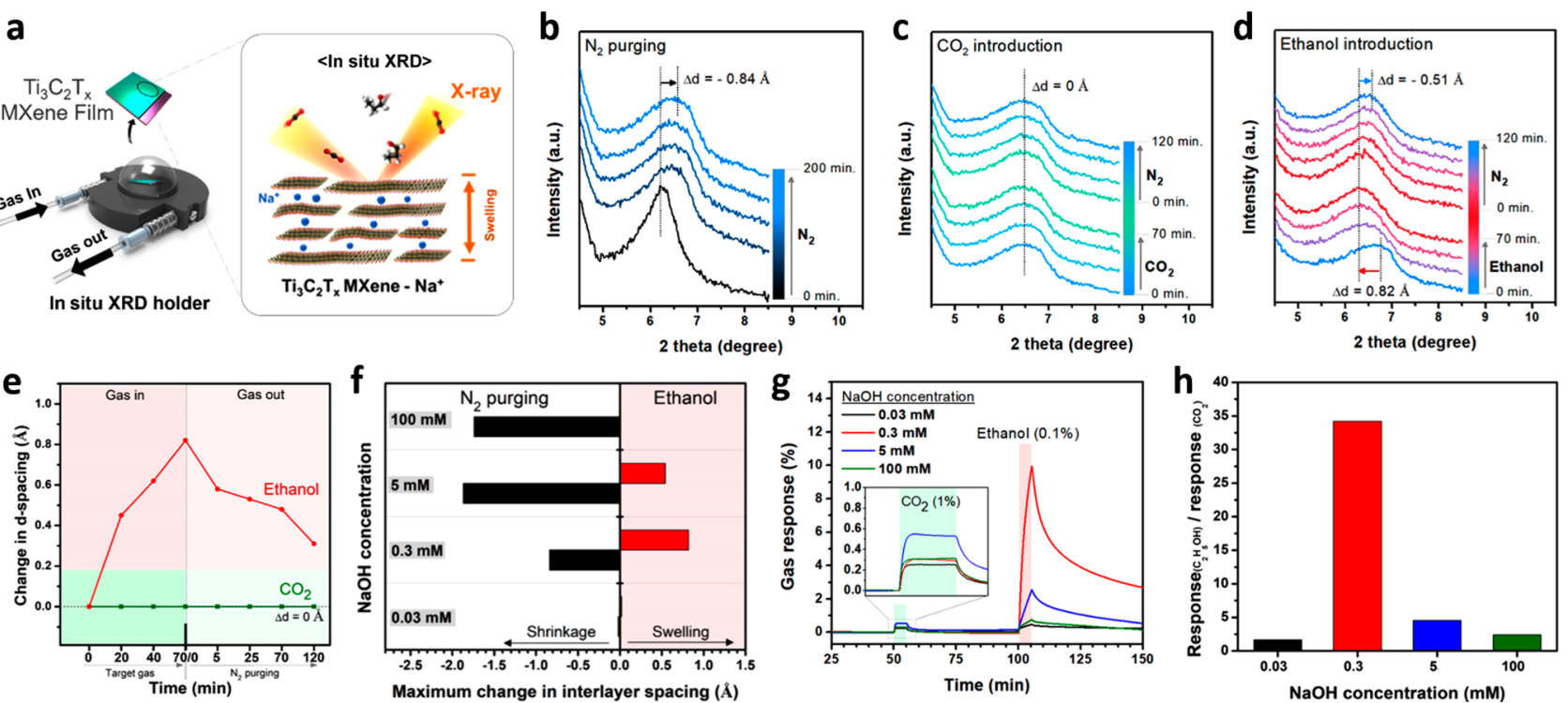

Figure 8. (a) Schematic illustration of in-situ XRD analysis of $\mathrm{Na}^{+}$intercalated $\mathrm{Ti}_{3} \mathrm{C}_{2} \mathrm{~T}_{x}$ MXene film upon gas introduction. (b-d) The (002) peak shift of $0.3 \mathrm{mM} \mathrm{NaOH}$-treated $\mathrm{Ti}_{3} \mathrm{C}_{2} \mathrm{~T}_{x}$ MXene film during initial $\mathrm{N}_{2}$ purging (panel (b)), introduction of nonreactive $\mathrm{CO}_{2}$ gas (panel (c)), and reactive ethanol gas (panel (d)), followed by $\mathrm{N}_{2}$ purging. (e) Summary of the interlayer distance upon $\mathrm{CO}_{2}$ and ethanol exposure. (f) Shrinkage and swelling behavior of $\mathrm{Ti}_{3} \mathrm{C}_{2} \mathrm{~T}_{x}$ MXene film treated with different $\mathrm{NaOH}$ solution concentrations upon exposure of $\mathrm{N}_{2}$ and ethanol. (g) Resistance variation of $\mathrm{Na}^{+}$intercalated $\mathrm{Ti}_{3} \mathrm{C}_{2} \mathrm{~T}_{x}$ films. (h) Ethanol selectivity of the $\mathrm{Na}^{+}$intercalated $\mathrm{Ti}_{3} \mathrm{C}_{2} \mathrm{~T}_{x} \mathrm{MXene}$ gas sensor toward $\mathrm{CO}_{2}$ gas. [Reproduced, with permission, from ref 74. Copyright 2019, American Chemical Society, Washington, DC.]

their gas sensing mechanism are the obvious remaining questions.

Koh et al. have investigated the effect of $\mathrm{Na}^{+}$cation intercalation in $\mathrm{Ti}_{3} \mathrm{C}_{2} \mathrm{~T}_{x}$ MXene films and their corresponding gas sensing behavior (see Figure 8). ${ }^{74}$ The amount of intercalated $\mathrm{Na}^{+}$cation between MXene nanosheets plays an important role in their swelling behavior and selective gas sensing performance. Specifically, $\mathrm{Ti}_{3} \mathrm{C}_{2} \mathrm{~T}_{x}$ films were treated with different concentration of $\mathrm{NaOH}$ solutions $(0.03,0.3,5$, and $100 \mathrm{mM}$ ), and their structural change of interlayer spacing was observed using in-situ XRD methods under sequential exposure of nitrogen gas and ethanol vapor. MXene film treated with $0.03 \mathrm{mM} \mathrm{NaOH}$ solution did not show noticeable changes under both ambients. At $\mathrm{NaOH}$ concentrations of 0.3-5 mM, MXene shows reversible shrinkage and swelling behaviors, because of dehydration and ethanol intercalation, respectively. The ethanol intercalation is thermodynamically spontaneous and driven by hydrogen bonding formation with the surface functional groups of MXene and the intercalated water molecules. No swelling was found for $\mathrm{CO}_{2}$ gas, despite their smaller molecule size. At the higher $\mathrm{NaOH}$ concentration of $100 \mathrm{mM}$, similar dehydration was found without ethanol swelling. The initial dehydration upon nitrogen purging provided sites for ethanol intercalation sites; however, excessive $\mathrm{Na}^{+}$ions result in stabilization of the interlayer structure. Optimum $\mathrm{NaOH}$ concentration was found to be 0.3 $\mathrm{mM}$, where the highest swelling upon exposure of ethanol, hence, enhanced gas response and selectivity.

\section{PHOTONIC APPLICATIONS OF MXENES}

Intense surface plasmon (SP) excitations of $\mathrm{Ti}_{3} \mathrm{C}_{2} \mathrm{~T}_{x}$ MXene has first been investigated by Mauchamp et al. ${ }^{66}$ Unlike other 2D materials, a thickness-independent bulk plasmon energies are found from $\mathrm{Ti}_{3} \mathrm{C}_{2} \mathrm{~T}_{x}$ MXene, becauzse of their weak interlayer coupling. Later, El-Demellawi et al. successfully visualized the various SP modes using a combination of scanning transmission electron microscopy (STEM) and ultrahigh resolution electron energy loss spectroscopy (EELS) for individual single-layered and multilayered $\mathrm{Ti}_{3} \mathrm{C}_{2} \mathrm{~T}_{x}$ MXene. ${ }^{60} \mathrm{It}$ was discovered that inherent interband transition mode and transversal SP modes are invariant across the MXene flake, while longitudinal SP modes show a variation in their SP energies, depending on the shape, size, and thickness of $\mathrm{Ti}_{3} \mathrm{C}_{2} \mathrm{~T}_{x}$ flakes. Interestingly, each $\mathrm{Ti}_{3} \mathrm{C}_{2} \mathrm{~T}_{x}$ nanosheets in multilayer MXene retain their own plasmonic response, demonstrating independent polarizability that is attributed to their unusual weak interlayer coupling. Furthermore, the studied $\mathrm{Ti}_{3} \mathrm{C}_{2} \mathrm{~T}_{x}$ MXene flakes were vacuum annealed in situ, at temperatures up to $900{ }^{\circ} \mathrm{C}$, to monitor the change of the surface functionalization. At temperatures above $500{ }^{\circ} \mathrm{C}$, the desorption of fluorine was detected, which multiplies the metal-like free electron density of $\mathrm{Ti}_{3} \mathrm{C}_{2} \mathrm{~T}_{x}$ flakes. As a result, the SP energy of all modes was monotonically blue-shifted.

Alshareef et al. capitalized on these useful plasmonic features and used MXenes to fabricate plasmonic photodetectors that work in the visible portion of the spectrum. ${ }^{75}$ Specifically, five different MXenes- $\mathrm{Ti}_{2} \mathrm{CT}_{x}, \mathrm{Ti}_{3} \mathrm{C}_{2} \mathrm{~T}_{x}, \mathrm{Mo}_{2} \mathrm{CT}_{x}, \mathrm{Nb}_{2} \mathrm{CT}_{x}$, and $\mathrm{V}_{2} \mathrm{CT}_{x}$-were investigated for plasmonic photodetection (see Figure 9). ${ }^{75} \mathrm{Mo}_{2} \mathrm{CT}_{x}$ exhibited the best performance among the studied MXenes in the visible spectral region. The responsivity and detectivity reached $9 \mathrm{~A} \mathrm{~W}^{-1}$ and $5 \times 10^{11}$ Jones, respectively. The photocurrent in $\mathrm{Mo}_{2} \mathrm{CT}_{x}$ film was found to be highly dependent on their surface plasmon-assisted hot electrons. Specifically, a large photocurrent was found in the wavelength range of $400-650 \mathrm{~nm}$, which overlaps with the transverse surface plasmon energy of $\mathrm{Mo}_{2} \mathrm{CT}_{x}$ MXene. The maximum $I_{\text {on }} / I_{\text {off }}$ ratio of $\sim 200$ was found under incident light of $660 \mathrm{~nm}$ and a bias of $1 \mathrm{~V}$. Besides the high photodetection performance, the $\mathrm{Mo}_{2} \mathrm{CT}_{x}$ thin-film photodetector shows excellent stability under continuous illumination and repeated mechanical stress. The detailed surface plasmon energies and distribution of $\mathrm{Mo}_{2} \mathrm{CT}_{x}$ were explored and visualized by EELS 

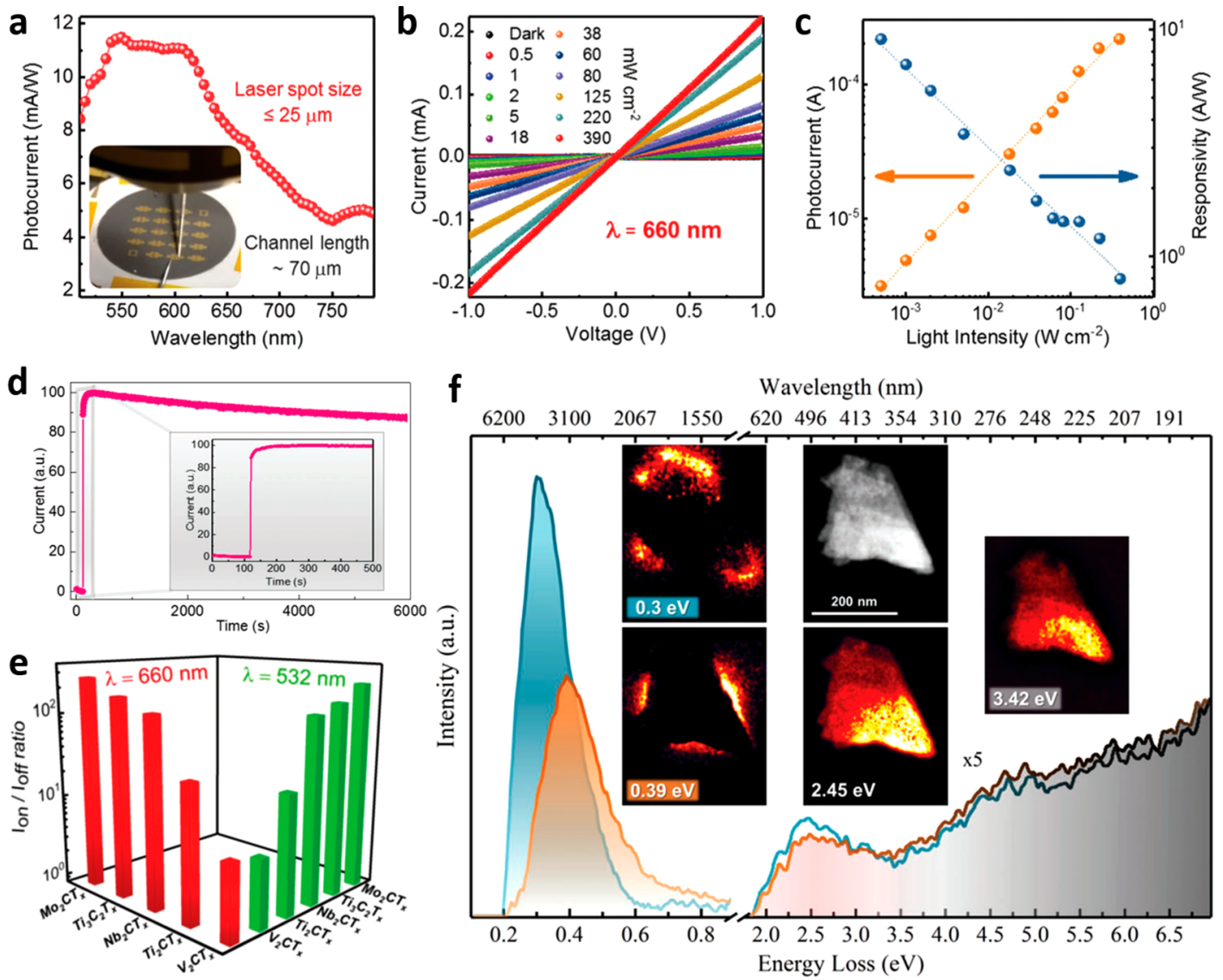

Figure 9. Photoresponse of $\mathrm{Mo}_{2} \mathrm{CT}_{x}$ MXene thin-film photodetectors. (a) Spectral photocurrent response under $0.7 \mathrm{~V}$ bias voltage. Inset is a photograph showing devices and measurement setup. (b) Linear current-voltage characteristics under different light intensities at a wavelength of $660 \mathrm{~nm}$. (c) Photocurrent and responsivity as a function of light intensity. (d) Photostability under continuous illumination. (e) $I_{\text {on }} / I_{\text {off }}$ ratio of five MXene photodetectors under excitation wavelengths of 660 and $532 \mathrm{~nm}$. (f) Zero-loss peak subtracted EELS spectra of a $\mathrm{Mo}_{2} \mathrm{CT}_{x}$ MXene with a truncated triangular shape. Inset figures show STEM-HAADF image and corresponding EELS fitted intensity mapping for different surface plasmonic energies: longitudinal dipole $(0.3 \mathrm{eV})$, longitudinal quadrupole $(0.39 \mathrm{eV})$, transversal mode $(2.45$ $\mathrm{eV})$, and interband transition $(3.42 \mathrm{eV})$. [Reproduced, with permission, from ref 75. Copyright 2019, Wiley-VCH Verlag GmbH \& Co. KGaA, Weinheim, Germany.]

mapping. Four distinct peaks were identified at 0.30, 0.39, 2.45, and $3.42 \mathrm{eV}$, which are assigned as longitudinal dipole, longitudinal quadrupole, transversal modes, and interband transition, respectively. Note that such multipolar surface plasmon modes have not been found in any other $2 \mathrm{D}$ materials, but only in MXenes. The longitudinal and transversal surface plasmon energies of MXenes are known to be further tuned by controlling the population of surface termination groups from the case of $\mathrm{Ti}_{3} \mathrm{C}_{2} \mathrm{~T}_{x}$ MXene, ${ }^{60}$ which strongly relate with the free electron density of MXenes. The longitudinal dipole and quadrupole modes are also dependent on the morphology of each flake. Because of the weak interlayer interaction of MXene, each monolayer MXene flakes preserves their own surface plasmon modes as isolated sheets in the multilayer film, allowing successful fabrication of broadband plasmonic photodetection.

Hydrothermal method has also been utilized to synthesize MXene quantum dots (MQDs) with photoluminescence (PL) property through a quantum confinement effect (Figures 10ad). ${ }^{76}$ The first $\mathrm{Ti}_{3} \mathrm{C}_{2} \mathrm{~T}_{x}$ MQDs have been prepared by a hydrothermal process using ammonia solution $(\mathrm{pH} \sim 9)$ at 100,120 , and $150{ }^{\circ} \mathrm{C}$ for $6 \mathrm{~h}$, resulting in average particle size of 2.9, 3.7, and $6.2 \mathrm{~nm}$, respectively. Most of the prepared MQDs were found to have a monolayer thickness of $\sim 1 \mathrm{~nm}$.
The MQDs showed excitation-dependent PL behavior with a quantum yield of up to $\sim 10 \%$. The hydrothermal temperature also tunes the structure of MQDs; the pristine structure of MXene was retained up to $100^{\circ} \mathrm{C}$, a hybrid structure of $\mathrm{Ti}-\mathrm{C}$ core and $\mathrm{TiO}_{2}$ surface was obtained at $120^{\circ} \mathrm{C}$, and amorphous carbon dots were obtained at $150{ }^{\circ} \mathrm{C}$. The formal two cases were found to have low cytotoxicity, and their application in multicolor cellular imaging was demonstrated. The PL intensity of all three MQDs is independent of $\mathrm{pH}$, suggesting the surface passivation by $-\mathrm{NH}$ groups.

Recently, $\mathrm{Ti}_{3} \mathrm{C}_{2} \mathrm{~T}_{x}$ MQDs with white $\mathrm{PL}$ and two-photon fluorescence (TPFL) has been synthesized via a solvothermal method (see Figures $10 \mathrm{e}-\mathrm{h}){ }^{77}$ In this study, oleylamine (OLA) was used, instead of water, as an exfoliation medium and surface passivation agent. The synthesized MQDs with an average size of $13.1 \mathrm{~nm}$ show a highly preserved chemical structure of parent MXene, because of the low reaction temperature, surface passivation by $-\mathrm{NH}$ groups, reducing environment of OLA, ${ }^{85}$ and the absence of water. Under UV light excitation with the wavelength of $360 \mathrm{~nm}$, MQDs dispersed in ethanol exhibits a strong PL centered at $509 \mathrm{~nm}$ with a wide full width at half maximum (FWHM) of $220 \mathrm{~nm}$, which covers all the visible range. The photoluminescence quantum yield reaches $9.36 \%$ established by a synergic 

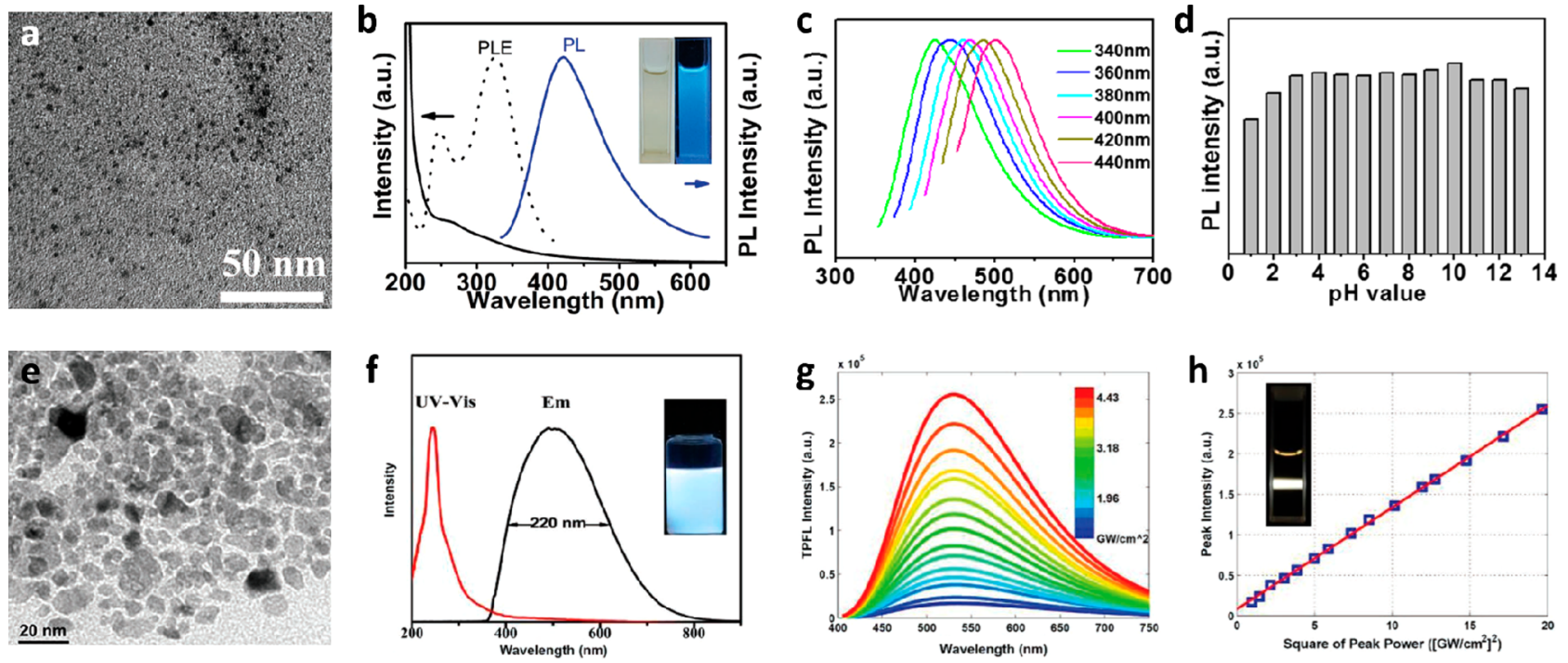

Figure 10. $\mathrm{Ti}_{3} \mathrm{C}_{2} \mathrm{~T}_{x}$ MXene quantum dots (MQD) with photoluminescence property. (a-d) MQDs synthesized via a hydrothermal method at $100{ }^{\circ} \mathrm{C}$ (TEM image (panel (a)), and UV-vis absorption, photoluminescence excitation (PLE), and photoluminescence (PL) spectra (excitation wavelength of $320 \mathrm{~nm}$ ) of MQDs in aqueous solution (panel (b))). Insets show results obtained under visible light and illumination with $365 \mathrm{~nm}$ UV lamp. Excitation-dependent PL spectra of MQDs (panel (c)), and pH-dependent PL intensity (panel (d)). [Reproduced, with permission, from ref 76. Copyright 2017, Wiley-VCH Verlag GmbH \& Co. KGaA, Weinheim, Germany.] (e, f) MQDs synthesized by a solvothermal method using oleylamine at $80{ }^{\circ} \mathrm{C}$ (TEM image (panel (e)), and UV-vis absorption and fluorescence emission (excitation wavelength of $360 \mathrm{~nm}$ ) of MQDs in ethanol solution (panel (f))). Inset photograph has been obtained under UV light. (g) Twophoton fluorescence (TPFL) spectra under different excitation laser intensities at $800 \mathbf{n m}$ femtosecond pulsed laser, and the quadratic relationship between TPFL emission intensity and the excitation laser intensity. Inset photograph has been obtained under $800 \mathrm{~nm}$ laser. [Reproduced, with permission, from ref 77, under the Creative Commons Attribution 4.0 International License (CC BY 4.0). Copyright 2019, Wiley-VCH Verlag GmbH \& Co. KGaA, Weinheim, Germany.]
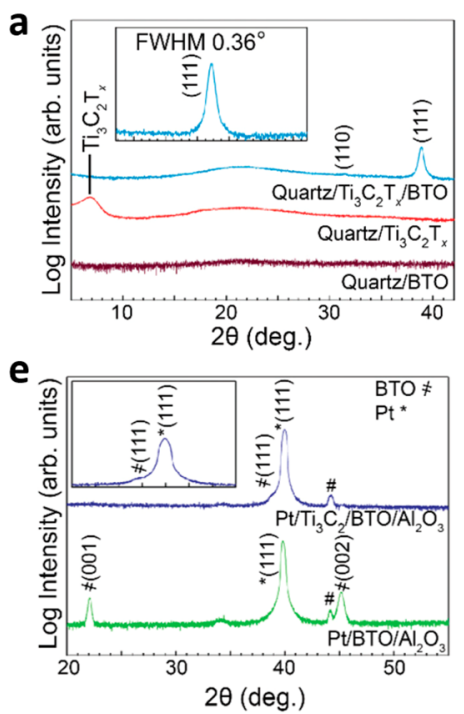

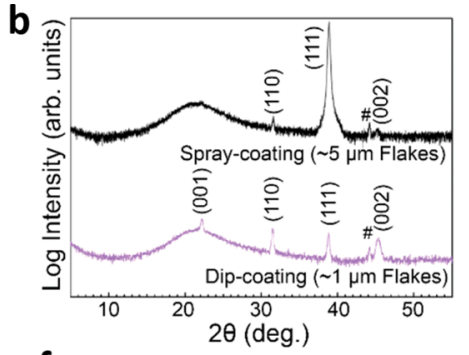

f

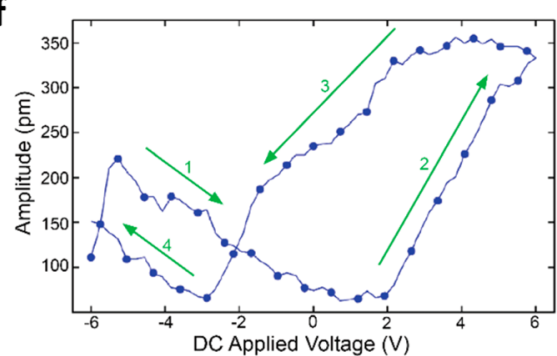

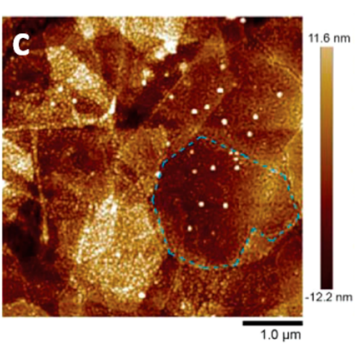
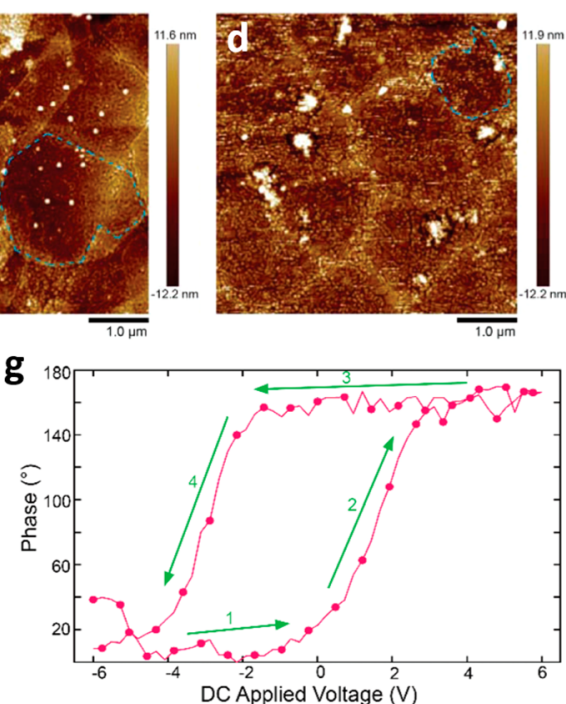

Figure 11. (a) XRD patterns of $\mathrm{BaTiO}_{3}$ (BTO) films deposited on amorphous quartz substrates with and without $\mathrm{Ti}_{3} \mathrm{C}_{2} \mathrm{~T}_{x} \mathrm{MXene}$ layer. (b) XRD patterns of BTO films on quartz substrates with different deposition methods and the size of MXene flakes. (c, d) Scanning probe microscopy (SPM) images of BTO films grown on spray-coated MXene film with an average flake size of $5 \mu \mathrm{m}$ (panel (c)), and dip-coated MXene film with an average flake size of $1 \mu \mathrm{m}$ (panel (d)). (e) XRD patterns of BTO films on (111) Pt-silicon surface with and without MXene layer. The hashtag symbol (\#) denotes a peak from the sample stage. ( $f, g$ ) Switching spectroscopy piezoresponse force microscopy (SS-PFM) response of $\mathrm{Pt}-\mathrm{Si} / \mathrm{Ti}_{3} \mathrm{C}_{2} \mathrm{~T}_{x} / \mathrm{BTO}$ samples for amplitude (panel (f)) and phase (panel $(\mathrm{g})$ ). [Reproduced, with permission, from ref 78. Copyright 2019, The Royal Society of Chemistry, London.]

contribution of $\mathrm{Ti}_{3} \mathrm{C}_{2} \mathrm{~T}_{x}$ MXene core and surface-state-linked OLA chains. More importantly, TPFL properties were found where the MQDs show a similar white luminescence spectrum under a near-infrared femtosecond pulsed layer of $800 \mathrm{~nm}$.

\section{MXENES TEMPLATES FOR CRYSTAL GROWTH}

$\mathrm{Ti}_{3} \mathrm{C}_{2} \mathrm{~T}_{x}$ MXene films have been used as a temporal growth template for van der Waals epitaxy growth of highly (111) oriented $\mathrm{BaTiO}_{3}$ film by pulsed laser deposition (Figure 11). ${ }^{78}$ Because of the highly $c$-oriented restacking nature of MXene 
a

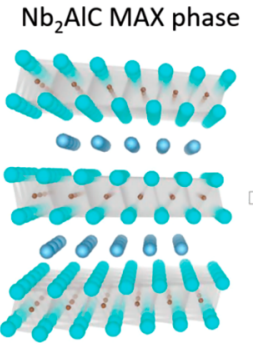

$\mathrm{Nb}_{2} \mathrm{C}$ MXene

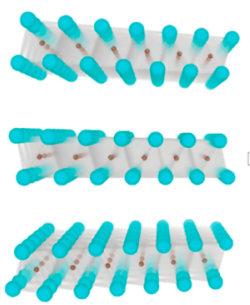

$\mathrm{KNbO}_{3}$ crystal

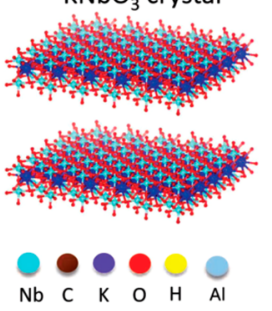

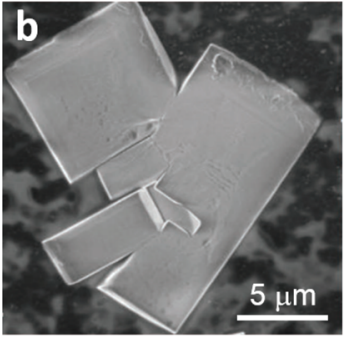
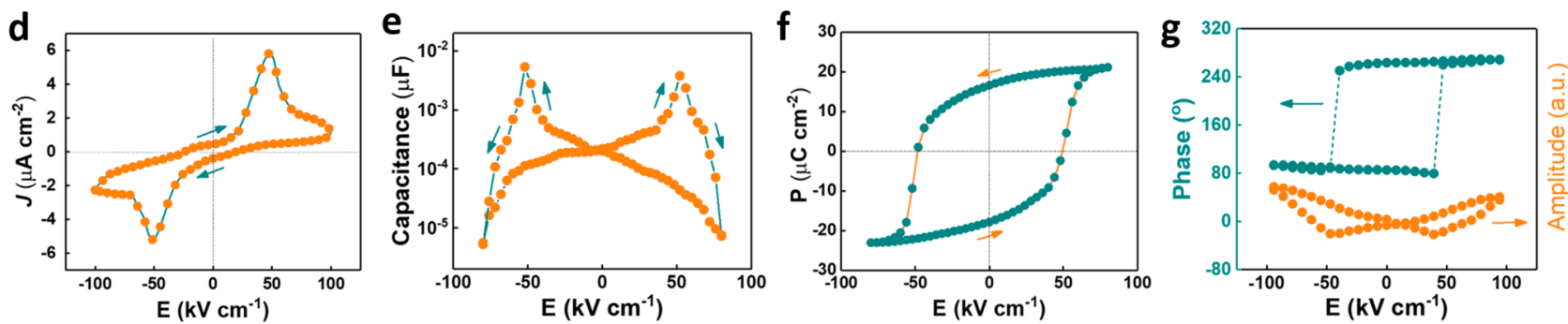

Figure 12. (a) Crystal structure of the parent $\mathrm{Nb}_{2} \mathrm{AlC}$ MAX phase, $\mathrm{Nb}_{2} \mathrm{CT}_{x}$ MXene after selective etching of the Al layer, and $\mathrm{MXene-derived}$

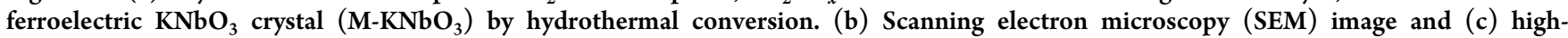
resolution transmission electron microscopy (TEM) image of $\mathrm{M}-\mathrm{KNbO}_{3}$. Inset shows selected-area electron diffraction patterns along the [001] direction. (d-g) Ferroelectric measurements of $\mathrm{M}-\mathrm{KNbO}_{3}$ crystals at RT. Current density versus electric field $(J-E)($ panel $(\mathrm{d}))$, and capacitance versus electric field $(\mathrm{C}-\mathrm{E})$ (panel (e)) of $\mathrm{Pt} / \mathrm{M}-\mathrm{KNbO}_{3} / \mathrm{Pt}$ device. Ferroelectric hysteresis loop of $\mathrm{M}-\mathrm{KNbO}_{3} \mathrm{crystal}$ at $10 \mathrm{~Hz}$ (panel (f)), and the corresponding PFM phase and amplitude hysteresis loops (panel (g)). [Reproduced, with permission, from ref 79. Copyright 2019, Wiley-VCH Verlag GmbH \& Co. KGaA, Weinheim, Germany.]

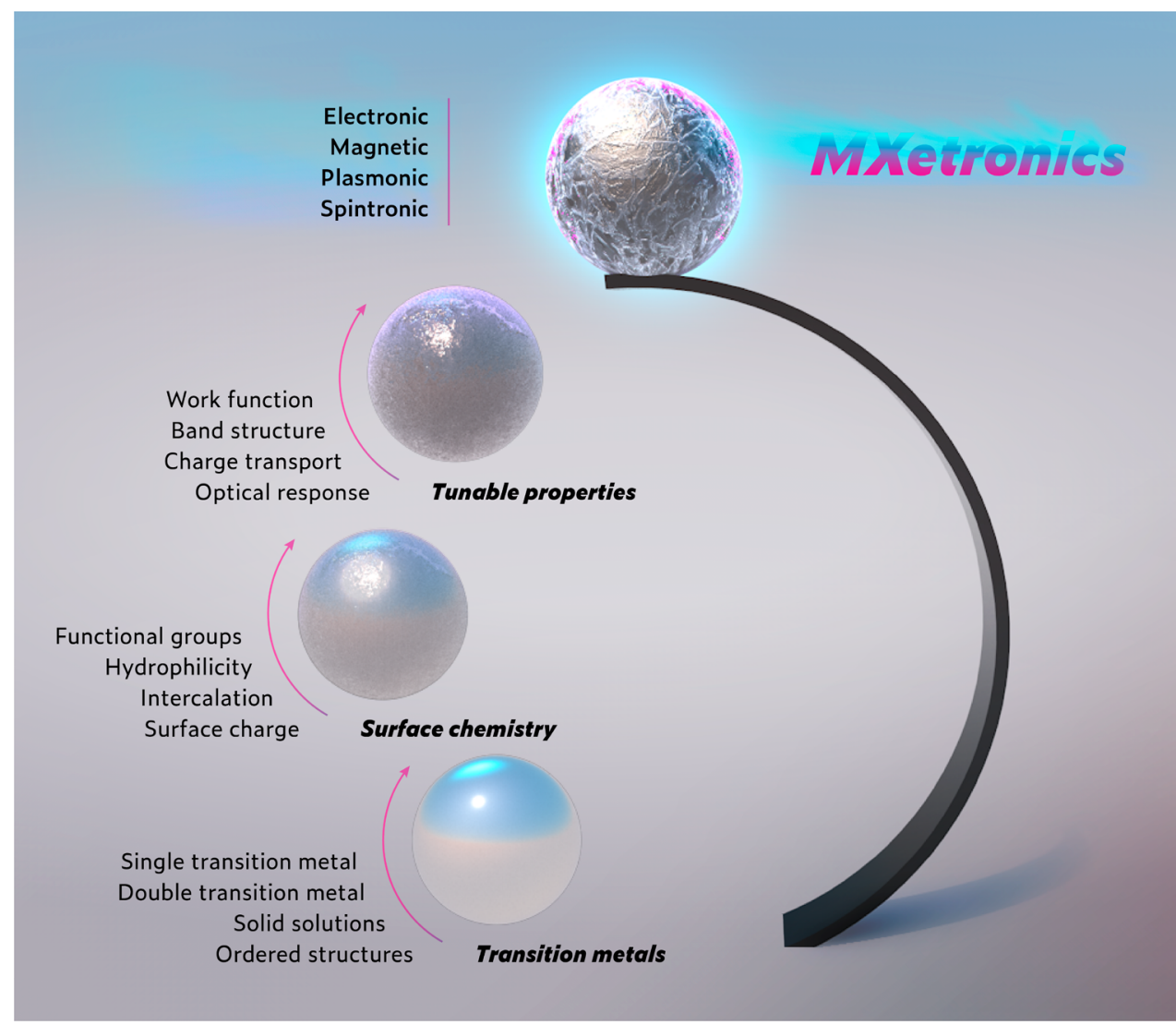

Figure 13. Schematic illustration of the important issues and relationships in MXetronics. The composition and surface chemistry of MXene are critical to tuning the the electronic and optical properties. The surface functional groups can be controlled by synthesis conditions and various treatments. Many novel devices are expected, based on the diverse family of MXenes.

films and their hexagonal geometry in the basal plane, $\mathrm{BaTiO}_{3}$ perovskite film can be grown along the (111) direction on
MXene seed layer, regardless of the crystallinity of the underlying substrate. The lattice parameters of $\mathrm{BaTiO}_{3}$ films 
are similar to their bulk values, implying an unstrained state of van der Waals epitaxy film. The size of MXene flakes also affects the orientation of $\mathrm{BaTiO}_{3}$ films: $5-\mu \mathrm{m}$-sized spraycoated MXene films result in (111)-dominant growth, while 1$\mu$ m-sized dip-coated MXene films resulted in the mixed orientation of (001), (110), and (111) on amorphous quartz substrates. The surface morphology of $\mathrm{BaTiO}_{3}$ films preserves the shape of MXene flakes. $\mathrm{BaTiO}_{3}$ films grow along the (001) direction on the (111) Pt-silicon substrate, whereas the growth direction is completely converted to (111) with the MXene seed layer. More importantly, $\mathrm{Ti}_{3} \mathrm{C}_{2} \mathrm{~T}_{x}$ MXene film is subject to full decomposition during deposition at $700{ }^{\circ} \mathrm{C}$ in an oxygen-rich ambient atmosphere, where the $\mathrm{Ti}$ atoms can incorporate into the $\mathrm{BaTiO}_{3}$ film. The resulting films grown on the MXene layer retain their dielectric constant and ferroelectric behavior.

Ferroelectric crystals of potassium niobate $\left(\mathrm{KNbO}_{3}\right)$ with a high aspect ratio and uniform shape have been synthesized by using $\mathrm{Nb}_{2} \mathrm{CT}_{x}$ MXene as precursor material in a hydrothermal conversion method (Figure 12). ${ }^{79} \mathrm{Nb}_{2} \mathrm{CT}_{x}$ MXene was subjected to simultaneous oxidation and alkalization during the hydrothermal process in potassium hydroxide $(\mathrm{KOH})$ solution with sodium dodecyl sulfate (SDS) surfactant at 190 ${ }^{\circ} \mathrm{C}$ for $48 \mathrm{~h}$. The MXene-derived $\mathrm{KNbO}_{3}$ crystals exhibited robust ferroelectric properties at RT, such as a saturated polarization, a remnant polarization, and a coercive field of 21 $\mu \mathrm{C} \mathrm{cm}{ }^{-2}, 17 \mu \mathrm{C} \mathrm{cm}^{-2}$, and $50 \mathrm{kV} \mathrm{cm}{ }^{-1}$, respectively. Under the same conduction, the use of nonlayered commercial $\mathrm{NbC}$ powder, instead of $\mathrm{Nb}_{2} \mathrm{CT}_{x}$ MXene, results in cubelike $\mathrm{KNbO}_{3}$ powders with nonuniform size distribution. Without the presence of SDS surfactant, the shape of the final products is irregular. The successful synthesis of high-aspect-ratio $\mathrm{KNbO}_{3}$ ferroelectric crystal was based on the 2D layered structure of $\mathrm{Nb}_{2} \mathrm{CT}_{x}$ MXene and shape-modulation effect of SDS. Basically, the $\mathrm{KNbO}_{3}$ inherits the $2 \mathrm{D}$ nature of MXene, resulting in a highly textured crystal morphology.

\section{SUMMARY AND OUTLOOK}

MXetronics is an emerging field covering electronic, optoelectronic, and sensing applications. Despite several important developments, we believe the field is still in its infancy, and many important discoveries remain to be made. Given the large number of different MXene compositions and possible surface terminations, MXenes with variable band structures, work functions, and bandgap energies promise huge potential in many applications.

Going forward, we feel that more work is needed on new MXene compositions and surface chemistry modification, which are the key parameters to achieve a wide coverage of tunable properties. (See Figure 13.) Detailed and controllable studies are desired on the impact of such modification on the fundamental properties of MXenes and MXene-based devices. Plasma, chemical, and thermal treatment present possible approaches to modify MXene surfaces. These treatments can be used to tailor the MXene work function, which then enables its utilization to make devices such as Schottky junctions or Ohmic contacts for transistors, diodes, solar cells, and photodetectors. The surface terminations may affect other properties, such as the plasmonic behavior, thermoelectric properties, and photothermal properties of MXenes.

Simulations suggest some MXenes such as $\mathrm{Sc}_{2} \mathrm{CT}_{x}, \mathrm{Ti}_{2} \mathrm{CO}_{2}$, $\mathrm{Zr}_{2} \mathrm{CO}_{2}$, and $\mathrm{Hf}_{2} \mathrm{CO}_{2}$ have large semiconductor band gaps, which opens a new field of research and potential new phenomena, such as all-MXene 2D devices, field-effect devices, Schottky junctions, and memory devices. More work should be dedicated to the development of nonmetallic MXenes. The experimental realization of semiconducting MXene films remains a challenge at this stage of MXene development using solution chemistry routes. Direct growth of MXene film via physical deposition methods seems to be difficult from the viewpoint of thermodynamics; however, an epitaxially grown $\mathrm{Ti}_{3} \mathrm{AlC}_{2}$ MAX phase film has been reported using sputtering. ${ }^{86}$ In another approach, high-quality ultrathin $\alpha-\mathrm{Mo}_{2} \mathrm{C}$ superconducting crystals have been synthesized via a chemical vapor deposition (CVD) process. ${ }^{87}$ Although the crystal structure of CVD-grown 2D transition-metal carbide is slightly different from that of $\mathrm{Mo}_{2} \mathrm{CT}_{x}$ MXene, CVD may be a good option to achieve high-quality MXene films with precise control of surface functional groups for MXetronics.

Recently, some simulations have suggested $\mathrm{Mn}_{2} \mathrm{C}(\mathrm{OH})_{2}$, $\mathrm{Mn}_{2} \mathrm{CF}_{2}, \mathrm{Ti}_{2} \mathrm{NO}_{2}, \mathrm{Cr}_{2} \mathrm{NO}_{2}$, and $\mathrm{Mn}_{2} \mathrm{NT}_{x}$ MXenes as ferromagnetic half-metals. These types of MXenes are potentially important in the area of spintronics research; however, experimental confirmation is required. This would also enable new functionalities and new generations of MXene devices. Double transition-metal MXenes are another important class of materials that have hardly been explored for MXetronics. The carrier concentration and type, conductivity, work function, band gaps, and surface plasmons can all be tuned by changing the combination of transition metals used in the compound. This can lead to drastic improvements in the performance of electronic and photonic devices based on MXenes.

The hydrophilic nature of $\mathrm{Ti}_{3} \mathrm{C}_{2} \mathrm{~T}_{x}$ MXene allow their use in low-cost solution-processed device fabrication, because of the existence of surface functional groups and high conductive nature, unlike the complicated conversion process from graphite to reduced graphene oxide. The work function of MXene can be controlled using several different methods and should be studied in more detail. Effects of parameters such as synthesis conditions, post-synthesis heat treatment, molecular doping, and chemical treatment on work function should be thoroughly evaluated. Making MXene contact with a tunable work function can enable many types of electronic devices. The unexpected tunable multipolar surface plasmons of MXenes should also be an active area of research and further developed for novel optical communication and sensing applications. The photoluminescent MXene quantum dots have shown some initial promise in light-emitting devices, bioimaging, and even for laser cooling through two-photon fluorescence. The use of MXene as precursors and templates for van der Waals epitaxial growth may realize many unstrained functional thin films in their closed-packed orientation, regardless of the substrate crystallinity. High-aspect-ratio single crystals with robust ferroelectric properties have been synthesized by the hydrothermal conversion of MXene. Other types of MXene-driven functional crystals are possibly obtained that should also be explored in more detail. In conclusion, when it comes to MXetronics, we believe that the best is yet to come.

\section{AUTHOR INFORMATION}

\section{Corresponding Author}

*E-mail: husam.alshareef@kaust.edu.sa. 


\section{ORCID $\odot$}

Hyunho Kim: 0000-0003-2381-9716

Husam N. Alshareef: 0000-0001-5029-2142

Notes

The authors declare no competing financial interest.

\section{ACKNOWLEDGMENTS}

This work was supported by King Abdullah University of Science and Technology (KAUST).

\section{REFERENCES}

(1) Anasori, B.; Lukatskaya, M. R.; Gogotsi, Y. 2D metal carbides and nitrides (MXenes) for energy storage. Nat. Rev. Mater. 2017, 2, 16098.

(2) Alhabeb, M.; Maleski, K.; Anasori, B.; Lelyukh, P.; Clark, L.; Sin, S.; Gogotsi, Y. Guidelines for Synthesis and Processing of TwoDimensional Titanium Carbide $\left(\mathrm{Ti}_{3} \mathrm{C}_{2} \mathrm{~T}_{\mathrm{X}}\right.$ MXene). Chem. Mater. 2017, 29, 7633-7644.

(3) Anasori, B.; Xie, Y.; Beidaghi, M.; Lu, J.; Hosler, B. C.; Hultman, L.; Kent, P. R. C.; Gogotsi, Y.; Barsoum, M. W. Two-Dimensional, Ordered, Double Transition Metals Carbides (MXenes). ACS Nano 2015, 9, 9507-9516.

(4) Naguib, M.; Kurtoglu, M.; Presser, V.; Lu, J.; Niu, J.; Heon, M.; Hultman, L.; Gogotsi, Y.; Barsoum, M. W. Two-Dimensional Nanocrystals Produced by Exfoliation of $\mathrm{Ti}_{3} \mathrm{AlC}_{2}$. Adv. Mater. 2011, $23,4248-4253$.

(5) Lukatskaya, M. R.; Kota, S.; Lin, Z.; Zhao, M.-Q.; Shpigel, N.; Levi, M. D.; Halim, J.; Taberna, P.-L.; Barsoum, M. W.; Simon, P.; Gogotsi, Y. Ultra-high-rate pseudocapacitive energy storage in twodimensional transition metal carbides. Nat. Energy 2017, 2, 17105.

(6) Xia, Y.; Mathis, T. S.; Zhao, M.-Q.; Anasori, B.; Dang, A.; Zhou, Z.; Cho, H.; Gogotsi, Y.; Yang, S. Thickness-independent capacitance of vertically aligned liquid-crystalline MXenes. Nature 2018, 557, 409-412.

(7) Zhang, J. Q.; Zhao, Y. F.; Guo, X.; Chen, C.; Dong, C. L.; Liu, R. S.; Han, C. P.; Li, Y. D.; Gogotsi, Y.; Wang, G. X. Single platinum atoms immobilized on an MXene as an efficient catalyst for the hydrogen evolution reaction. Nat. Catal. 2018, 1, 985-992.

(8) Ran, J.; Gao, G.; Li, F.-T.; Ma, T.-Y.; Du, A.; Qiao, S.-Z. $\mathrm{Ti}_{3} \mathrm{C}_{2}$ MXene co-catalyst on metal sulfide photo-absorbers for enhanced visible-light photocatalytic hydrogen production. Nat. Commun. 2017, 8, 13907.

(9) Seh, Z. W.; Fredrickson, K. D.; Anasori, B.; Kibsgaard, J.; Strickler, A. L.; Lukatskaya, M. R.; Gogotsi, Y.; Jaramillo, T. F.; Vojvodic, A. Two-Dimensional Molybdenum Carbide (MXene) as an Efficient Electrocatalyst for Hydrogen Evolution. ACS Energy Lett. 2016, 1, 589-594.

(10) Gao, G.; O'Mullane, A. P.; Du, A. 2D MXenes: A New Family of Promising Catalysts for the Hydrogen Evolution Reaction. ACS Catal. 2017, 7, 494-500.

(11) Zhang, Q.; Teng, J.; Zou, G.; Peng, Q.; Du, Q.; Jiao, T.; Xiang, J. Efficient phosphate sequestration for water purification by unique sandwich-like MXene/Magnetic iron oxide nanocomposites. Nanoscale 2016, 8, 7085-7093.

(12) Shahzad, F.; Alhabeb, M.; Hatter, C. B.; Anasori, B.; Hong, S. M.; Koo, C. M.; Gogotsi, Y. Electromagnetic interference shielding with 2D transition metal carbides (MXenes). Science 2016, 353, $1137-1140$

(13) Zhang, C.; Anasori, B.; Seral-Ascaso, A.; Park, S.-H.; McEvoy, N.; Shmeliov, A.; Duesberg, G. S.; Coleman, J. N.; Gogotsi, Y.; Nicolosi, V. Transparent, Flexible, and Conductive 2D Titanium Carbide (MXene) Films with High Volumetric Capacitance. Adv. Mater. 2017, 29, 1702678.

(14) Kim, S. J.; Koh, H.-J.; Ren, C. E.; Kwon, O.; Maleski, K.; Cho, S.-Y.; Anasori, B.; Kim, C.-K.; Choi, Y.-K.; Kim, J.; Gogotsi, Y.; Jung, H.-T. Metallic $\mathrm{Ti}_{3} \mathrm{C}_{2} \mathrm{~T}_{\mathrm{x}}$ MXene Gas Sensors with Ultrahigh Signal-toNoise Ratio. ACS Nano 2018, 12, 986-993.
(15) Zhang, Y.-Z.; Lee, K. H.; Anjum, D. H.; Sougrat, R.; Jiang, Q.; Kim, H.; Alshareef, H. N. MXenes stretch hydrogel sensor performance to new limits. Sci. Adv. 2018, 4, eaat0098.

(16) Liu, Y.; Guo, J.; Zhu, E.; Liao, L.; Lee, S.-J.; Ding, M.; Shakir, I.; Gambin, V.; Huang, Y.; Duan, X. Approaching the Schottky-Mott limit in van der Waals metal-semiconductor junctions. Nature 2018, $557,696-700$.

(17) Kim, H.; Wang, Z. W.; Alshareef, H. N. MXetronics: Electronic and photonic applications of MXenes. Nano Energy 2019, 60, 179197.

(18) Liu, Y.; Stradins, P.; Wei, S.-H. Van der Waals metalsemiconductor junction: Weak Fermi level pinning enables effective tuning of Schottky barrier. Sci. Adv. 2016, 2, No. e1600069.

(19) Khazaei, M.; Arai, M.; Sasaki, T.; Ranjbar, A.; Liang, Y. Y.; Yunoki, S. OH-terminated two-dimensional transition metal carbides and nitrides as ultralow work function materials. Phys. Rev. B: Condens. Matter Mater. Phys. 2015, 92, No. 075411.

(20) Liu, Y.; Xiao, H.; Goddard, W. A. Schottky-Barrier-Free Contacts with Two-Dimensional Semiconductors by Surface-Engineered MXenes. J. Am. Chem. Soc. 2016, 138, 15853-15856.

(21) Tahini, H. A.; Tan, X.; Smith, S. C. The origin of low workfunctions in $\mathrm{OH}$ terminated MXenes. Nanoscale 2017, 9, 70167020.

(22) Khazaei, M.; Arai, M.; Sasaki, T.; Chung, C.-Y.; Venkataramanan, N. S.; Estili, M.; Sakka, Y.; Kawazoe, Y. Novel Electronic and Magnetic Properties of Two-Dimensional Transition Metal Carbides and Nitrides. Adv. Funct. Mater. 2013, 23, 21852192.

(23) Khazaei, M.; Ranjbar, A.; Arai, M.; Sasaki, T.; Yunoki, S. Electronic properties and applications of MXenes: a theoretical review. J. Mater. Chem. C 2017, 5, 2488-2503.

(24) Frey, N. C.; Kumar, H.; Anasori, B.; Gogotsi, Y.; Shenoy, V. B. Tuning Noncollinear Spin Structure and Anisotropy in Ferromagnetic Nitride MXenes. ACS Nano 2018, 12, 6319-6325.

(25) Kumar, H.; Frey, N. C.; Dong, L.; Anasori, B.; Gogotsi, Y.; Shenoy, V. B. Tunable Magnetism and Transport Properties in Nitride MXenes. ACS Nano 2017, 11, 7648-7655.

(26) Liu, J.-H.; Kan, X.; Amin, B.; Gan, L.-Y.; Zhao, Y. Theoretical exploration of the potential applications of Sc-based MXenes. Phys. Chem. Chem. Phys. 2017, 19, 32253-32261.

(27) Zha, X.-H.; Luo, K.; Li, Q.; Huang, Q.; He, J.; Wen, X.; Du, S. Role of the surface effect on the structural, electronic and mechanical properties of the carbide MXenes. Europhys. Lett. 2015, 111, 26007.

(28) Kumar, S.; Schwingenschlogl, U. Thermoelectric performance of functionalized $\mathrm{Sc}_{2} \mathrm{C}$ MXenes. Phys. Rev. B: Condens. Matter Mater. Phys. 2016, 94, No. 035405.

(29) Lee, Y.; Hwang, Y.; Chung, Y.-C. Achieving Type I, II, and III Heterojunctions Using Functionalized MXene. ACS Appl. Mater. Interfaces 2015, 7, 7163-7169.

(30) Hong, L.; Klie, R. F.; Ogut, S. First-principles study of size- and edge-dependent properties of MXene nanoribbons. Phys. Rev. B: Condens. Matter Mater. Phys. 2016, 93, 115412.

(31) Chandrasekaran, A.; Mishra, A.; Singh, A. K. Ferroelectricity, Antiferroelectricity, and Ultrathin 2D Electron/Hole Gas in Multifunctional Monolayer MXene. Nano Lett. 2017, 17, 3290-3296.

(32) Khazaei, M.; Arai, M.; Sasaki, T.; Estili, M.; Sakka, Y. Twodimensional molybdenum carbides: potential thermoelectric materials of the MXene family. Phys. Chem. Chem. Phys. 2014, 16, 7841-7849.

(33) Ma, Z.; Hu, Z.; Zhao, X.; Tang, Q.; Wu, D.; Zhou, Z.; Zhang, L. Tunable Band Structures of Heterostructured Bilayers with Transition-Metal Dichalcogenide and MXene Mono layer. J. Phys. Chem. C 2014, 118, 5593-5599.

(34) Xie, Y.; Kent, P. Hybrid density functional study of structural and electronic properties of functionalized $\mathrm{Ti}_{\mathrm{n}+1} \mathrm{X}_{\mathrm{n}}(\mathrm{X}=\mathrm{C}, \mathrm{N})$ monolayers. Phys. Rev. B: Condens. Matter Mater. Phys. 2013, 87, 235441.

(35) Gandi, A. N.; Alshareef, H. N.; Schwingenschlogl, U. Thermoelectric Performance of the MXenes $\mathrm{M}_{2} \mathrm{CO}_{2}(\mathrm{M}=\mathrm{Ti}, \mathrm{Zr}$, or Hf). Chem. Mater. 2016, 28, 1647-1652. 
(36) Zhang, H.; Yang, G.; Zuo, X.; Tang, H.; Yang, Q.; Li, G. Computational studies on the structural, electronic and optical properties of graphene-like MXenes $\left(\mathrm{M}_{2} \mathrm{CT}_{2}, \mathrm{M}=\mathrm{Ti}, \mathrm{Zr}, \mathrm{Hf} ; \mathrm{T}=\mathrm{O}\right.$, $\mathrm{F}, \mathrm{OH})$ and their potential applications as visible-light driven photocatalysts. J. Mater. Chem. A 2016, 4, 12913-12920.

(37) Zha, X.-H.; Huang, Q.; He, J.; He, H.; Zhai, J.; Francisco, J. S.; $\mathrm{Du}, \mathrm{S}$. The thermal and electrical properties of the promising semiconductor MXene $\mathrm{Hf}_{2} \mathrm{CO}_{2}$. Sci. Rep. 2016, 6, 27971.

(38) Yang, J.; Zhou, X.; Luo, X.; Zhang, S.; Chen, L. Tunable electronic and magnetic properties of $\mathrm{Cr}_{2} \mathrm{M}^{\prime} \mathrm{C}_{2} \mathrm{~T}_{2}\left(\mathrm{M}^{\prime}=\mathrm{Ti}\right.$ or $\mathrm{V}$; $\mathrm{T}=\mathrm{O}, \mathrm{OH}$ or F). Appl. Phys. Lett. 2016, 109, 203109.

(39) Si, C.; Zhou, J.; Sun, Z. Half-Metallic Ferromagnetism and Surface Functionalization-Induced Metal-Insulator Transition in Graphene-like Two-Dimensional $\mathrm{Cr}_{2} \mathrm{C}$ Crystals. ACS Appl. Mater. Interfaces 2015, 7, 17510-17515.

(40) Weng, H.; Ranjbar, A.; Liang, Y.; Song, Z.; Khazaei, M.; Yunoki, S.; Arai, M.; Kawazoe, Y.; Fang, Z.; Dai, X. Large-gap twodimensional topological insulator in oxygen functionalized MXene. Phys. Rev. B: Condens. Matter Mater. Phys. 2015, 92, No. 075436.

(41) He, J. J.; Lyu, P. B.; Nachtigall, P. New two-dimensional Mnbased MXenes with room-temperature ferromagnetism and halfmetallicity. J. Mater. Chem. C 2016, 4, 11143-11149.

(42) Khazaei, M.; Wang, V.; Sevik, C.; Ranjbar, A.; Arai, M.; Yunoki, $\mathrm{S}$. Electronic structures of iMAX phases and their two-dimensional derivatives: A family of piezoelectric materials. Phys. Rev. Mater. 2018, 2, No. 074002.

(43) Lind, H.; Halim, J.; Simak, S. I.; Rosen, J. Investigation of vacancy-ordered $\mathrm{Mo}_{1.33} \mathrm{C}$ MXene from first principles and x-ray photoelectron spectroscopy. Phys. Rev. Mater. 2017, 1, No. 044002.

(44) Zha, X.-H.; Zhou, J.; Luo, K.; Lang, J.; Huang, Q.; Zhou, X.; Francisco, J. S.; He, J.; Du, S. Controllable magnitude and anisotropy of the electrical conductivity of $\mathrm{Hf}_{3} \mathrm{C}_{2} \mathrm{O}_{2}$ MXene. J. Phys.: Condens. Matter 2017, 29, 165701.

(45) Dong, L.; Kumar, H.; Anasori, B.; Gogotsi, Y.; Shenoy, V. B. Rational Design of Two-Dimensional Metallic and Semiconducting Spintronic Materials Based on Ordered Double-Transition-Metal MXenes. J. Phys. Chem. Lett. 2017, 8, 422-428.

(46) Zhang, J.-J.; Lin, L.; Zhang, Y.; Wu, M.; Yakobson, B. I.; Dong, S. Type-II Multiferroic $\mathrm{Hf}_{2} \mathrm{VC}_{2} \mathrm{~F}_{2}$ MXene Monolayer with High Transition Temperature. J. Am. Chem. Soc. 2018, 140, 9768-9773.

(47) Khazaei, M.; Ranjbar, A.; Arai, M.; Yunoki, S. Topological insulators in the ordered double transition metals $\mathrm{M}_{2}^{\prime} \mathrm{M}^{\prime \prime} \mathrm{C}_{2}$ MXenes $\left(\mathrm{M}^{\prime}=\mathrm{Mo}, \mathrm{W} ; \mathrm{M}\right.$ " = Ti, Zr, Hf). Phys. Rev. B: Condens. Matter Mater. Phys. 2016, 94, 125152.

(48) Si, C.; Jin, K. H.; Zhou, J.; Sun, Z.; Liu, F. Large-Gap Quantum Spin Hall State in MXenes: d-Band Topological Order in a Triangular Lattice. Nano Lett. 2016, 16, 6584-6591.

(49) Sun, W. W.; Xie, Y.; Kent, P. R. C. Double transition metal MXenes with wide band gaps and novel magnetic properties. Nanoscale 2018, 10, 11962-11968.

(50) Halim, J.; Persson, I.; Moon, E. J.; Kuhne, P.; Darakchieva, V.; Persson, P. O. A.; Eklund, P.; Rosen, J.; Barsoum, M. W. Electronic and optical characterization of $2 \mathrm{D} \mathrm{Ti}_{2} \mathrm{C}$ and $\mathrm{Nb}_{2} \mathrm{C}$ (MXene) thin films. J. Phys.: Condens. Matter 2019, 31, 165301.

(51) Ghidiu, M.; Lukatskaya, M. R.; Zhao, M.-Q.; Gogotsi, Y.; Barsoum, M. W. Conductive two-dimensional titanium carbide 'clay' with high volumetric capacitance. Nature 2014, 516, 78-81.

(52) Eda, G.; Yamaguchi, H.; Voiry, D.; Fujita, T.; Chen, M. W.; Chhowalla, M. Photoluminescence from Chemically Exfoliated $\mathrm{MoS}_{2}$. Nano Lett. 2011, 11, 5111-5116.

(53) Ghidiu, M.; Halim, J.; Kota, S.; Bish, D.; Gogotsi, Y.; Barsoum, M. W. Ion-Exchange and Cation Solvation Reactions in $\mathrm{Ti}_{3} \mathrm{C}_{2}$ MXene. Chem. Mater. 2016, 28, 3507-3514.

(54) Hart, J. L.; Hantanasirisakul, K.; Lang, A. C.; Anasori, B.; Pinto, D.; Pivak, Y.; van Omme, J. T.; May, S. J.; Gogotsi, Y.; Taheri, M. L. Control of MXenes' electronic properties through termination and intercalation. Nat. Commun. 2019, 10, 522.
(55) Kim, H.; Anasori, B.; Gogotsi, Y.; Alshareef, H. N. Thermoelectric Properties of Two-Dimensional Molybdenum-Based MXenes. Chem. Mater. 2017, 29, 6472-6479.

(56) Schultz, T.; Frey, N. C.; Hantanasirisakul, K.; Park, S.; May, S. J.; Shenoy, V. B.; Gogotsi, Y.; Koch, N. Surface Termination Dependent Work Function and Electronic Properties of $\mathrm{Ti}_{3} \mathrm{C}_{2} \mathrm{~T}_{\mathrm{x}}$ MXene. Chem. Mater. 2019, 31, 6590-6597.

(57) Hantanasirisakul, K.; Alhabeb, M.; Lipatov, A.; Maleski, K.; Anasori, B.; Salles, P.; Ieosakulrat, C.; Pakawatpanurut, P.; Sinitskii, A.; May, S. J.; Gogotsi, Y. Effects of Synthesis and Processing on Optoelectronic Properties of Titanium Carbonitride MXene. Chem. Mater. 2019, 31, 2941-2951.

(58) Ghidiu, M.; Kota, S.; Halim, J.; Sherwood, A. W.; Nedfors, N.; Rosen, J.; Mochalin, V. N.; Barsoum, M. W. Alkylammonium Cation Intercalation into $\mathrm{Ti}_{3} \mathrm{C}_{2}$ (MXene): Effects on Properties and IonExchange Capacity Estimation. Chem. Mater. 2017, 29, 1099-1106.

(59) Wang, Z.; Kim, H.; Alshareef, H. N. Oxide Thin-Film Electronics using All-MXene Electrical Contacts. Adv. Mater. 2018, 30, 1706656.

(60) El-Demellawi, J. K.; Lopatin, S.; Yin, J.; Mohammed, O. F.; Alshareef, H. N. Tunable Multipolar Surface Plasmons in $2 \mathrm{D} \mathrm{Ti}_{3} \mathrm{C}_{2} \mathrm{~T}_{\mathrm{x}}$ MXene Flakes. ACS Nano 2018, 12, 8485-8493.

(61) Tu, S.; Jiang, Q.; Zhang, X.; Alshareef, H. N. Large Dielectric Constant Enhancement in MXene Percolative Polymer Composites. ACS Nano 2018, 12, 3369-3377.

(62) Persson, I.; Naslund, L. A.; Halim, J.; Barsoum, M. W.; Darakchieva, V.; Palisaitis, J.; Rosen, J.; Persson, P. O. A. On the organization and thermal behavior of functional groups on $\mathrm{Ti}_{3} \mathrm{C}_{2}$ MXene surfaces in vacuum. 2D Mater. 2018, 5, No. 015002.

(63) Xu, J.; Shim, J.; Park, J. H.; Lee, S. MXene Electrode for the Integration of $\mathrm{WSe}_{2}$ and $\mathrm{MoS}_{2}$ Field Effect Transistors. Adv. Funct. Mater. 2016, 26, 5328-5334.

(64) Lai, S.; Jang, S. K.; Cho, J. H.; Lee, S. Organic field-effect transistors integrated with $\mathrm{Ti}_{2} \mathrm{CT}_{\mathrm{X}}$ electrodes. Nanoscale 2018, 10, 5191-5197.

(65) Dillon, A. D.; Ghidiu, M. J.; Krick, A. L.; Griggs, J.; May, S. J.; Gogotsi, Y.; Barsoum, M. W.; Fafarman, A. T. Highly Conductive Optical Quality Solution-Processed Films of 2D Titanium Carbide. Adv. Funct. Mater. 2016, 26, 4162-4168.

(66) Mauchamp, V.; Bugnet, M.; Bellido, E. P.; Botton, G. A.; Moreau, P.; Magne, D.; Naguib, M.; Cabioc'h, T.; Barsoum, M. W. Enhanced and tunable surface plasmons in two-dimensional $\mathrm{Ti}_{3} \mathrm{C}_{2}$ stacks: Electronic structure versus boundary effects. Phys. Rev. B: Condens. Matter Mater. Phys. 2014, 89, 235428.

(67) Lipatov, A.; Lu, H. D.; Alhabeb, M.; Anasori, B.; Gruverman, A.; Gogotsi, Y.; Sinitskii, A. Elastic properties of $2 \mathrm{D} \mathrm{Ti}_{3} \mathrm{C}_{2} \mathrm{~T}_{\mathrm{x}}$ MXene monolayers and bilayers. Sci. Adv. 2018, 4, eaat0491.

(68) Lyu, B.; Kim, M.; Jing, H.; Kang, J.; Qian, C.; Lee, S.; Cho, J. H. Large-Area MXene Electrode Array for Flexible Electronics. ACS Nano 2019, 13, 11392-11400.

(69) Fu, H. C.; Ramalingam, V.; Kim, H.; Lin, C. H.; Fang, X. S.; Alshareef, H. N.; He, J. H. MXene-Contacted Silicon Solar Cells with 11.5\% Efficiency. Adv. Energy Mater. 2019, 9, 1900180.

(70) Yu, L. P.; Bati, A. S. R.; Grace, T. S. L.; Batmunkh, M.; Shapter, J. G. $\mathrm{Ti}_{3} \mathrm{C}_{2} \mathrm{~T}_{\mathrm{x}}$ (MXene)-Silicon Heterojunction for Efficient Photovoltaic Cells. Adv. Energy Mater. 2019, 9, 1901063.

(71) Agresti, A.; Pazniak, A.; Pescetelli, S.; Di Vito, A.; Rossi, D.; Pecchia, A.; Auf der Maur, M.; Liedl, A.; Larciprete, R.; Kuznetsov, D. V.; Saranin, D.; Di Carlo, A. Titanium-carbide MXenes for work function and interface engineering in perovskite solar cells. Nat. Mater. 2019, 18, 1228-1234.

(72) Ding, G. L.; Zeng, K. L.; Zhou, K.; Li, Z. X.; Zhou, Y.; Zhai, Y. B.; Zhou, L.; Chen, X. L.; Han, S. T. Configurable multi-state nonvolatile memory behaviors in $\mathrm{Ti}_{3} \mathrm{C}_{2}$ nanosheets. Nanoscale 2019, 11, $7102-7110$.

(73) Lee, E.; VahidMohammadi, A.; Yoon, Y. S.; Beidaghi, M.; Kim, D. J. Two-Dimensional Vanadium Carbide MXene for Gas Sensors with Ultrahigh Sensitivity Toward Nonpolar Gases. ACS Sens. 2019, 4, 1603-1611. 
(74) Koh, H. J.; Kim, S. J.; Maleski, K.; Cho, S. Y.; Kim, Y. J.; Ahn, C. W.; Gogotsi, Y.; Jung, H. T. Enhanced Selectivity of MXene Gas Sensors through Metal Ion Intercalation: In Situ X-ray Diffraction Study. ACS Sens. 2019, 4, 1365-1372.

(75) Velusamy, D. B.; El-Demellawi, J. K.; El-Zohry, A. M.; Giugni, A.; Lopatin, S.; Hedhili, M.; Mansour, A. M.; Fabrizio, E. D.; Mohammed, O. F.; Alshareef, H. N. MXenes for Plasmonic Photodetection. Adv. Mater. 2019, 31, 1807658.

(76) Xue, Q.; Zhang, H. J.; Zhu, M. S.; Pei, Z. X.; Li, H. F.; Wang, Z. F.; Huang, Y.; Huang, Y.; Deng, Q. H.; Zhou, J.; Du, S. Y.; Huang, Q.; Zhi, C. Y. Photoluminescent $\mathrm{Ti}_{3} \mathrm{C}_{2}$ MXene Quantum Dots for Multicolor Cellular Imaging. Adv. Mater. 2017, 29, 1604847.

(77) Lu, S. Y.; Sui, L. Z.; Liu, Y.; Yong, X.; Xiao, G. J.; Yuan, K. J.; Liu, Z. Y.; Liu, B. Z.; Zou, B.; Yang, B. White Photoluminescent $\mathrm{Ti}_{3} \mathrm{C}_{2}$ MXene Quantum Dots with Two-Photon Fluorescence. Adv. Sci. 2019, 6, 1801470 .

(78) Bennett-Jackson, A. L.; Falmbigl, M.; Hantanasirisakul, K.; Gu, Z. Q.; Imbrenda, D.; Plokhikh, A. V.; Will-Cole, A.; Hatter, C.; Wu, L. Y.; Anasori, B.; Gogotsi, Y.; Spanier, J. E. van der Waals epitaxy of highly (111)-oriented $\mathrm{BaTiO}_{3}$ on MXene. Nanoscale 2019, 11, 622630.

(79) Tu, S. B.; Ming, F. W.; Zhang, J. W.; Zhang, X. X.; Alshareef, H. N. MXene-Derived Ferroelectric Crystals. Adv. Mater. 2019, 31, 1806860.

(80) Kang, Z.; Ma, Y.; Tan, X.; Zhu, M.; Zheng, Z.; Liu, N.; Li, L.; Zou, Z.; Jiang, X.; Zhai, T.; Gao, Y. MXene-Silicon Van Der Waals Heterostructures for High-Speed Self-Driven Photodetectors. Adv. Electron. Mater. 2017, 3, 1700165.

(81) Satheeshkumar, E.; Makaryan, T.; Melikyan, A.; Minassian, H.; Gogotsi, Y.; Yoshimura, M. One-step Solution Processing of Ag, Au and Pd@MXene Hybrids for SERS. Sci. Rep. 2016, 6, 32049.

(82) Montazeri, K.; Currie, M.; Verger, L.; Dianat, P.; Barsoum, M. W.; Nabet, B. Beyond Gold: Spin-Coated $\mathrm{Ti}_{3} \mathrm{C}_{2}$-Based MXene Photodetectors. Adv. Mater. 2019, 31, 1903271.

(83) Yan, X.; Wang, K.; Zhao, J.; Zhou, Z.; Wang, H.; Wang, J.; Zhang, L.; Li, X.; Xiao, Z.; Zhao, Q.; Pei, Y.; Wang, G.; Qin, C.; Li, H.; Lou, J.; Liu, Q.; Zhou, P. A New Memristor with $2 \mathrm{D} \mathrm{Ti}_{3} \mathrm{C}_{2} \mathrm{~T}_{\mathrm{x}}$ MXene Flakes as an Artificial Bio-Synapse. Small 2019, 15, 1900107.

(84) Lee, E.; VahidMohammadi, A.; Prorok, B. C.; Yoon, Y. S.; Beidaghi, M.; Kim, D.-J. Room Temperature Gas Sensing of TwoDimensional Titanium Carbide (MXene). ACS Appl. Mater. Interfaces 2017, 9, 37184-37190.

(85) Mourdikoudis, S.; Liz-Marzan, L. M. Oleylamine in Nanoparticle Synthesis. Chem. Mater. 2013, 25, 1465-1476.

(86) Halim, J.; Lukatskaya, M. R.; Cook, K. M.; Lu, J.; Smith, C. R.; Naslund, L.- A.; May, S. J.; Hultman, L.; Gogotsi, Y.; Eklund, P.; Barsoum, M. W. Transparent Conductive Two-Dimensional Titanium Carbide Epitaxial Thin Films. Chem. Mater. 2014, 26, 2374-2381.

(87) Xu, C.; Wang, L.; Liu, Z.; Chen, L.; Guo, J.; Kang, N.; Ma, X.L.; Cheng, H.-M.; Ren, W. Large-area high-quality $2 \mathrm{D}$ ultrathin $\mathrm{Mo}_{2} \mathrm{C}$ superconducting crystals. Nat. Mater. 2015, 14, 1135-1141. 